\title{
Applying Human Factors Evaluation and Design Guidance to a Nuclear Power Plant Digital Control System
}

Thomas Ulrich, Ronald Boring, William Phoenix, Emily Dehority, Tim Whiting, Jonathan Morrell, Rhett Backstrom

August 2012

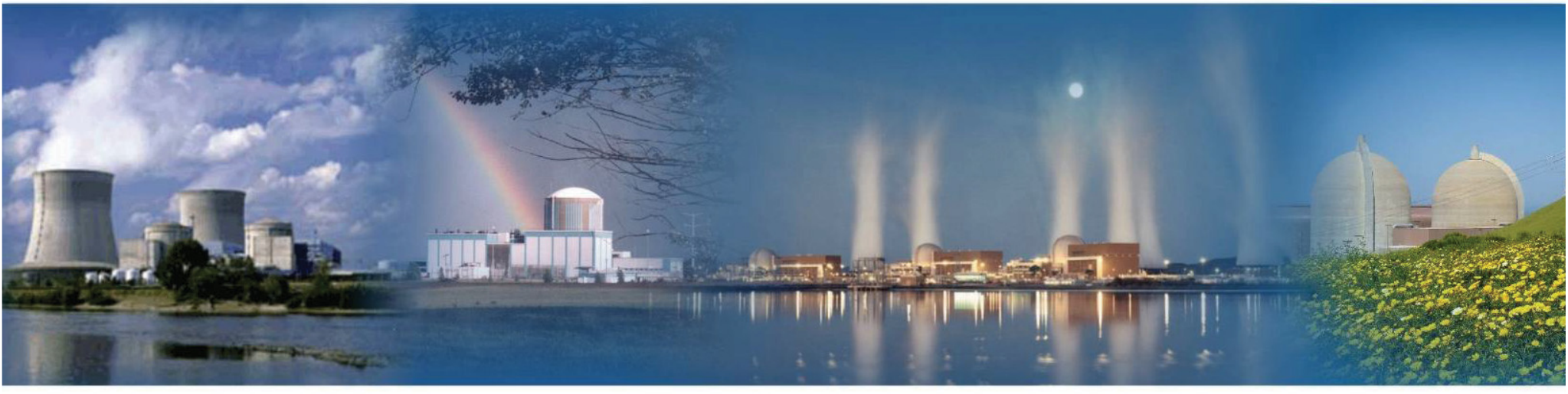

The INL is a U.S. Department of Energy National Laboratory operated by Battelle Energy Alliance 


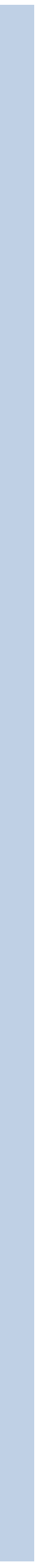




\section{DISCLAIMER}

This information was prepared as an account of work sponsored by an agency of the U.S. Government. Neither the U.S. Government nor any agency thereof, nor any of their employees, makes any warranty, expressed or implied, or assumes any legal liability or responsibility for the accuracy, completeness, or usefulness, of any information, apparatus, product, or process disclosed, or represents that its use would not infringe privately owned rights. References herein to any specific commercial product, process, or service by trade name, trade mark, manufacturer, or otherwise, does not necessarily constitute or imply its endorsement, recommendation, or favoring by the U.S. Government or any agency thereof. The views and opinions of authors expressed herein do not necessarily state or reflect those of the U.S. Government or any agency thereof. 

INL/EXT-12-26787

Revision 0

\section{Applying Human Factors Evaluation and Design Guidance to a Nuclear Power Plant Digital Control System}

Thomas Ulrich, Ronald Boring, William Phoenix, Emily Dehority, Tim Whiting, Jonathan Morrell, Rhett Backstrom

August 2012

Idaho National Laboratory

Idaho Falls, Idaho 83415

http://www.inl.gov

Prepared for the

U.S. Department of Energy

Office of Nuclear Energy

Under DOE Idaho Operations Office

Contract DE-AC07-05ID14517 



\section{EXECUTIVE SUMMARY}

The United States (U.S.) nuclear industry, like similar process control industries, has moved toward upgrading its control rooms. The upgraded control rooms typically feature digital control system (DCS) displays embedded in the panels. These displays gather information from the system and represent that information on a single display surface. In this manner, the DCS combines many previously separate analog indicators and controls into a single digital display, whereby the operators can toggle between multiple windows to monitor and control different aspects of the plant. The design of the DCS depends on the function of the system it monitors, but revolves around presenting the information most germane to an operator at any point in time. DCSs require a carefully designed human system interface. This report centers on redesigning existing DCS displays for an example chemical volume control system (CVCS) at a U.S. nuclear power plant.

The crucial nature of the CVCS, which controls coolant levels and boration in the primary system, requires a thorough human factors evaluation of its supporting DCS. The initial digital controls being developed for the DCSs tend to directly mimic the former analog controls. There are, however, unique operator interactions with a digital vs. analog interface, and the differences have not always been carefully factored in the translation of an analog interface to a replacement DCS.

To ensure safety, efficiency, and usability of the emerging DCSs, a human factors usability evaluation was conducted on a CVCS DCS currently being used and refined at an existing U.S. nuclear power plant. Subject matter experts from process control engineering, software development, and human factors evaluated the DCS displays to document potential usability issues and propose design recommendations. The evaluation yielded 167 potential usability issues with the DCS. These issues should not be considered operator performance problems but rather opportunities identified by experts to improve upon the design of the DCS. A set of nine design recommendations was developed to address these potential issues. The design principles addressed the following areas: (1) color, (2) pop-up window structure, (3) navigation, (4) alarms, (5) process control diagram, (6) gestalt grouping, (7) typography, (8) terminology, and (9) data entry. Visuals illustrating the improved DCS displays accompany the design recommendations. These nine design principles serve as the starting point to a planned general DCS style guide that can be used across the U.S. nuclear industry to aid in the future design of effective DCS interfaces. 


\section{ACKNOWLEDGMENTS}

This research was made possible through the generous availability of digital control system screens and tutorials by staff at a participating nuclear power plant. We would like to acknowledge their support of this effort and their willingness to share the results of our human factors review with a broader nuclear audience. We also thank members of the Light Water Reactor Sustainability Program, specifically Kathy McCarthy, Bruce Hallbert, Ken Thomas, and Magdy Tawfik, for their feedback on this report. We gratefully acknowledge the expert reviews provided by Jeffrey Joe, Vivek Agarwal, Craig Rieger, and Tim McJunkin of the Idaho National Laboratory. Finally, several of the authors of this report were student interns, and we express our thanks to their supervisors and instructors for providing highly competent contributors to this project. 


\section{CONTENTS}

EXECUTIVE SUMMARY

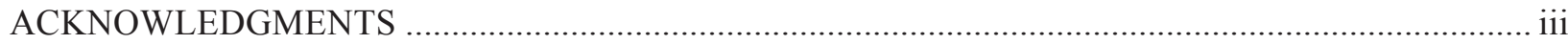

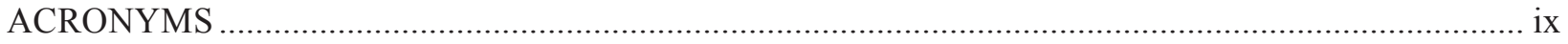

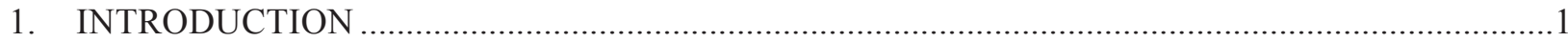

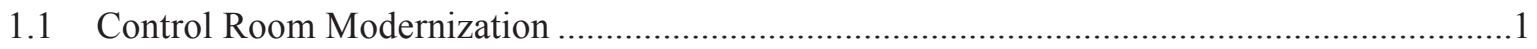

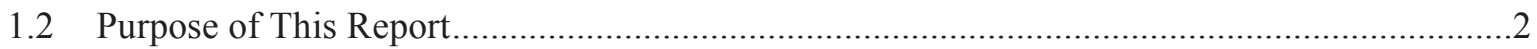

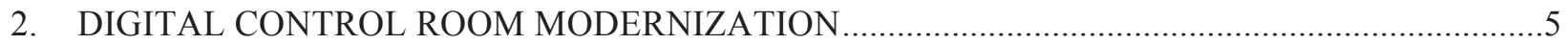

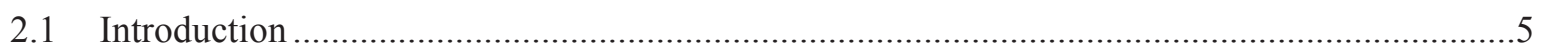

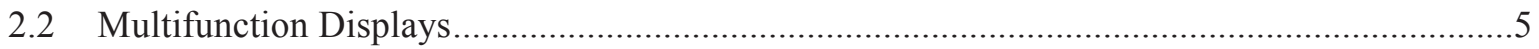

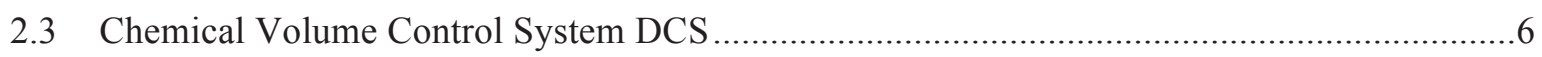

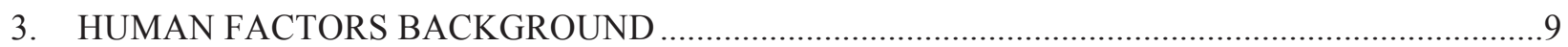

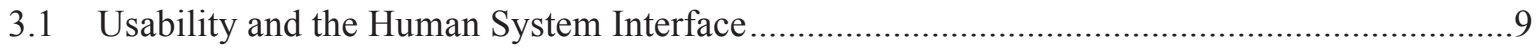

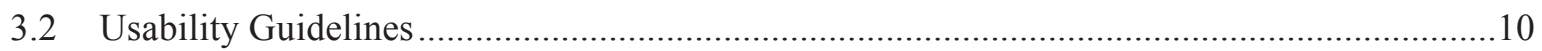

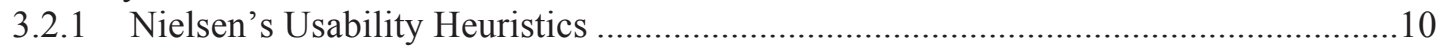

3.2.2 Gerhardt-Powal's Cognitive Engineering Principles.................................................11

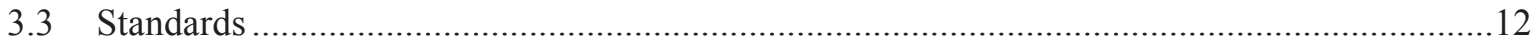

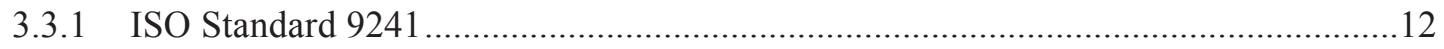

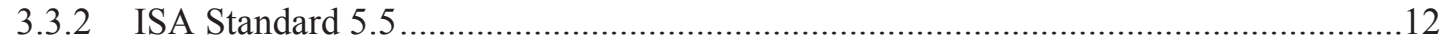

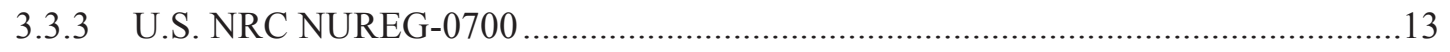

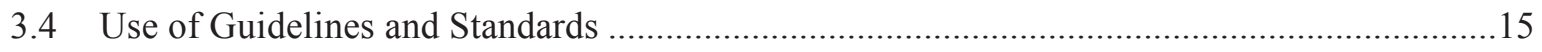

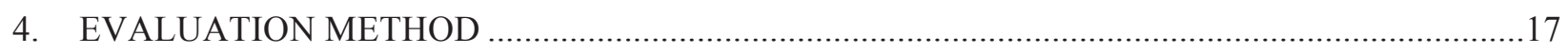

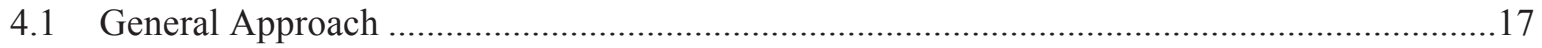

4.2 Heuristic, Standards, and Regulatory Guidance Evaluation .............................................. 17

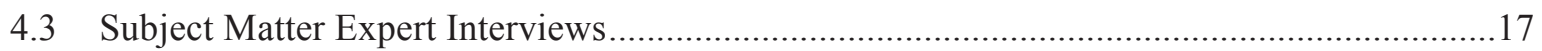

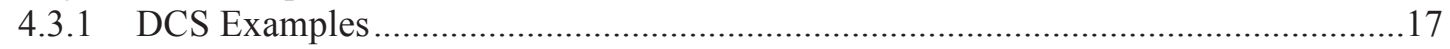

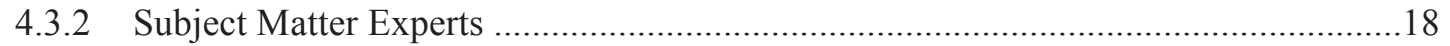

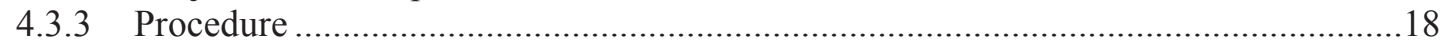

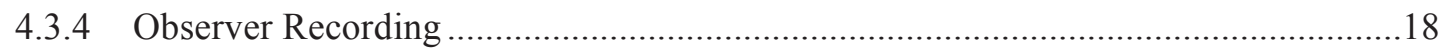

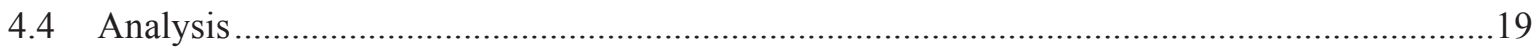

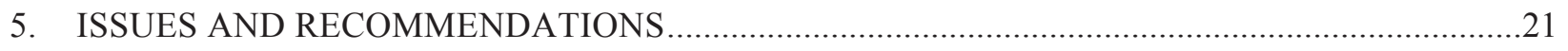

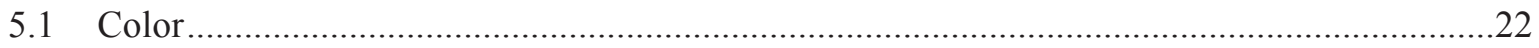

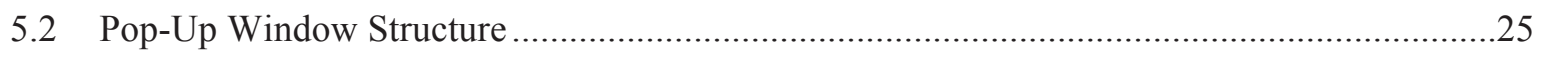

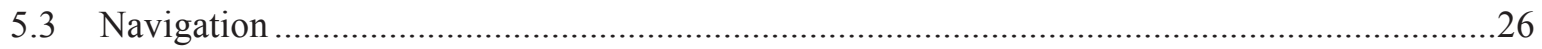

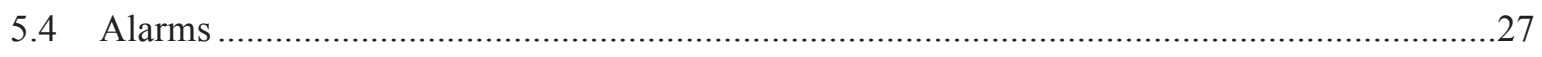

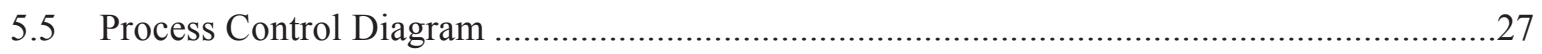

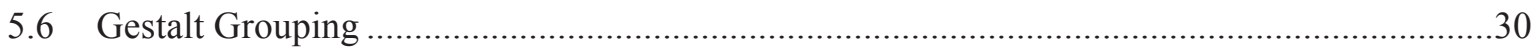

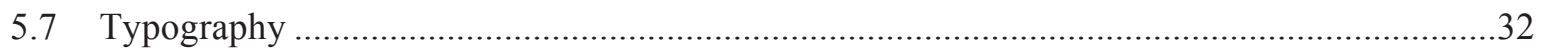




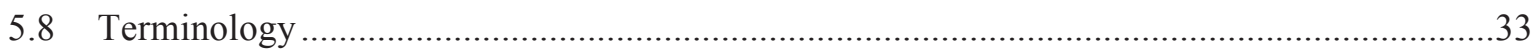

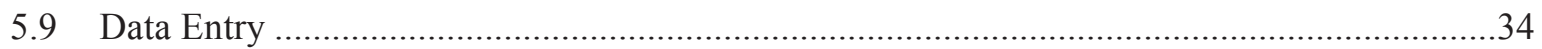

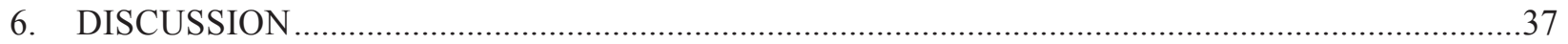

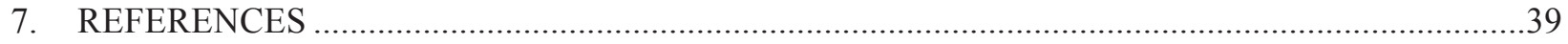

APPENDIX A: Description of DCS Display Prototype Tool................................................................ 


\section{FIGURES}

Figure 1. Chemical and Volume Control System Concept Map............................................................ 7

Figure 2. Reduced Color Examples for and Valves (a) and Pumps (b and c), Where Grey Replaces Red in Original DCS Screens .................................................................................... 23

Figure 3. Example of Dedicated Red Alarm Color in the DCS ........................................................... 23

Figure 4. Example Current Level Indicator (a) and Revised Level Indicator (b) .................................. 24

Figure 5. Current Colorful Pump Control Indication (a), Current Pop-Up Mode Selector (b), and New Dull Screen Mode Selector (c) ........................................................................................ 25

Figure 6. Designated Expanded View Pane for Pop-Up Windows and Alarms in Top Right of

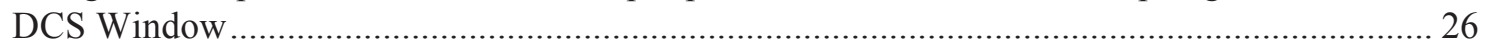

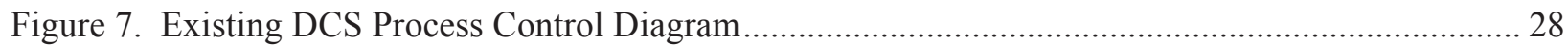

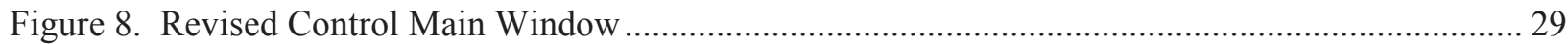

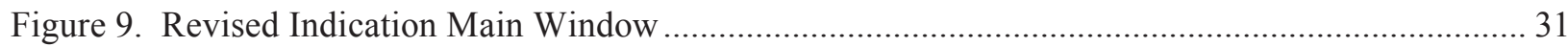

Figure 10. Alternate Boration Time Window in Current DCS ............................................................. 33

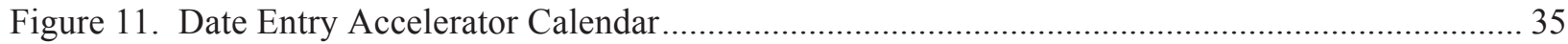

\section{TABLES}

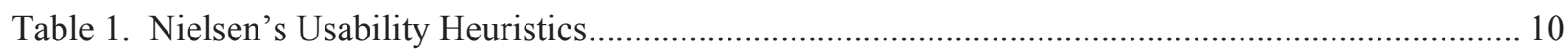

Table 2. Gerhard-Powal's Cognitive Engineering Principles ............................................................... 11

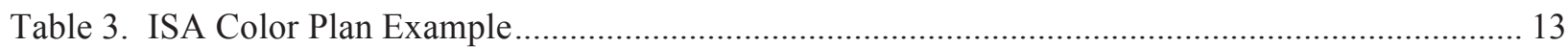

Table 4. Acceptable Color Associations and Characteristics from NUREG-0700 ................................. 14

Table 5. Example Evaluation Resulting from Usability Analysis ........................................................ 19

Table 6. Usability Issues and Design Recommendations ........................................................................ 21 


\section{ACRONYMS}

$\begin{array}{ll}\text { BAMU } & \text { boric acid makeup unit } \\ \text { CVCS } & \begin{array}{l}\text { chemical and volume control system } \\ \text { digital control system }\end{array} \\ \text { DCS } & \text { Department of Energy } \\ \text { DOE } & \text { Electrical Power Research Institute } \\ \text { EPRI } & \text { human-system interface } \\ \text { HSI } & \text { instrumentation and controls } \\ \text { I\&C } & \text { Idaho National Laboratory } \\ \text { INL } & \text { International Society of Automation } \\ \text { ISA } & \text { International Standards Organization } \\ \text { ISO } & \text { Light Water Reactor Sustainability } \\ \text { LWRS } & \text { main control room } \\ \text { MCR } & \text { multifunction displays } \\ \text { MFD } & \text { nuclear power plants } \\ \text { NPP } & \text { Nuclear Regulatory Commission } \\ \text { NRC } & \text { primary make-up water } \\ \text { PMW } & \text { reactor coolant system } \\ \text { RCS } & \text { steam generator } \\ \text { S/G } & \text { situation awareness } \\ \text { SA } & \text { subject matter expert } \\ \text { SME } & \text { United States } \\ \text { U.S. } & \text { volume control tank } \\ \text { VCT } & \text { visual display units } \\ \text { VDU } & \end{array}$




\section{INTRODUCTION}

\subsection{Control Room Modernization}

Commercial nuclear power plants (NPPs) in the United States (U.S.) largely predate the advent of significant digital systems in the control room. The legacy standard configuration for NPP control rooms consists of analog panels, whereby a group of reactor operators stand at these panels to monitor and manually control the plant. NPPs are receiving license extensions from the U.S. Nuclear Regulatory Commission (NRC), which allow the utilities to extend the useful life of the plant. Many systems and components are refreshed and replaced during this process to ensure the continued safe and reliable operation of the plant. As plant systems are upgraded, the corresponding controls of these systems must also be updated, requiring replacement of aging and obsolete analog controls originally associated with the plant systems by more capable digital control systems. Analog control panels are also in many cases at the end of their service life due to aging components and technical obsolescence, and utilities are currently reviewing ways to upgrade the main control rooms of NPPs.

As commercial utilities in the U.S. plan and carry out control room modernization efforts, there are many upgrade paths that are available in transitioning from analog panels to digital alternatives. The Electrical Power Research Institute (Naser et al., 2004) highlights four such paths:

- Piecemeal: Instrumentation and controls (I\&C) and the human-system interface (HSI) are replaced on a case-by-case basis as needed due to obsolescence, maintenance, or the requirement or desire for added functionality. This approach is typically not driven by an end-state vision for control room modernization but rather by the need to replace individual systems. As such, piecemeal upgrades sometimes result in what are known as digital islands - limited scope digital controls and indicators amid otherwise analog systems.

- Behind-the-Boards Modernization: I\&C is significantly upgraded to a modern digital backbone, while the HSI is maintained in its existing, analog state as without utilizing the capabilities that digital control systems and displays can offer. Behind-the-boards modernization may sometimes be conducted as a stepping stone to enable later HSI upgrades, even where HSI upgrades have not yet been formalized.

- Partially Modernized: Both I\&C and HSI are upgraded, while key elements of both are maintained in a partial legacy configuration. This approach results in what is known as a hybrid control room, with elements of the analog control room beside new digital controls and indicators. In many cases, the analog look and feel are maintained, while an entirely new digital backbone underlies a digital likefor-like replacement of the analog HSI, or the capabilities of the digital system are used to enhance the HSI. Digital control system (DCS) displays are typically integrated onto the control panels, allowing increased functionality. Some functions previously limited to the control panels may be integrated into operator workstations.

- Fully Modernized: Both I\&C and HSI are upgraded, and no legacy systems are maintained in place in the control room. With a full-scale modernization of the control room, there is the opportunity to reconsider the control panels, and designs may feature a shift to operator workstations with soft controls. With a fully upgraded digital backbone, there is significant opportunity to integrate information, and overview displays may be put in place of the control panels. No single standard for the fully digital control room exists, but most designs feature a considerably different mode of operations for licensed operators. 
A survey conducted by Joe et al. (2012), found that $80 \%$ of utility respondents believed piecemeal or partially modernized upgrades were the most cost effective approach short-term, meaning in the next 3-10 years of plant operation. Beyond 10 years, $80 \%$ of utility respondents believed that a fully modernized control room would prove most cost effective. Reconciling this disparity, $60 \%$ of utility respondents believed that a partially modernized approach would be realized for their plants, while only $20 \%$ believed their plant control rooms would be fully modernized. Utility respondents expressed concerns about regulatory resistance to plant upgrades, with $60 \%$ of utility respondents indicating that the behind-theboards modernization was, in their view, the approach most acceptable to the U.S. NRC. Seventy percent of utility respondents planned to continue to use panels in their control rooms, while $55 \%$ planned to integrate workstations as part of their control room modernization efforts.

\subsection{Purpose of This Report}

Due to tradeoffs between costs, competing technologies, and regulations, there is a clear need to support plants in defining their end-state vision and steps toward reaching that end-state vision. NPPs that are currently conducting only piecemeal control room upgrades would be better served to tie such upgrades together as part of a longer-term hybrid control room modernization effort. NPPs that are currently working toward a partial control room modernization strategy may benefit from additional guidance outlining benefits and providing mileposts toward full modernization.

The U.S. Department of Energy (DOE) Light Water Reactor Sustainability (LWRS) Program is engaged in helping utilities realize their plant modernization objectives. Within the LWRS framework, the pilot project on Control Room Modernization is specifically addressing ways to facilitate newer control rooms in support of plant life extension (Boring et al., 2012). The present report outlines efforts by the LWRS Control Room Modernization project to review current and under-development HSIs at a U.S. NPP. The HSIs consist of screens within a DCS that were developed in support of control room modernization. The research represented in this report consisted of expert reviews of the DCS displays by subject matter experts in process, human factors, and software development. The expert reviews identified potential improvements to the DCS displays.

This report provides background on the human factors evaluation approach used in this research effort and then highlights design recommendations based on human factors standards. This guidance serves as a partial high-level style guide to aid the plant in designing consistent and usable interfaces as they move forward with control room modernization efforts. This report also includes concrete design examples of the DCS displays, which may be adopted by utilities at NPPs. Finally, the appendix includes a description of the DCS display creation tool developed to support rapid prototyping of DCS displays for early stage evaluation by operators.

Only a single DCS system at a single plant was evaluated in the current research effort. As such, the design recommendations should not be seen as exhaustive but rather as a representative review and redesign of a current DCS system. The purpose of this report is to capture the human factors process employed in redesigning a set of DCS displays. The goals of this process were to ensure the DCS displays were:

- Usable - meaning operators would clearly understand the indicators and controls represented in the DCS;

- Consistent - meaning the elements of the DCS followed consistent patterns to avoid potential operator confusion and minimize DCS-specific training; 
- Optimized - meaning the DCS displays took advantage of the latest insights on information presentation to provide discernible, concise, and comprehensible displays; and

- Standards compliant - meaning the DCS displays adhered to existing HSI guidance, where available.

These goals and the process toward achieving them can serve as a template for utilities in designing new DCS displays as part of a partial or full control room modernization effort. Standardizing the process also ensures that urgent upgrade needs that might otherwise result in a piecemeal upgrade will be consistent with future modernization efforts.

This report completes the US DOE Level 3 milestone report requirement (M3LW-12IN0603072) under LWRS to "Develop digital displays in support of control room modernization." 


\section{DIGITAL CONTROL ROOM MODERNIZATION}

\subsection{Introduction}

NPPs are transitioning toward DCSs as analog components become obsolete and increasingly expensive to replace. Unlike analog control systems, DCSs use a computer to interpret the electrical signal communicated between system components (i.e., sensors and controllers) and the control system computer (Hollifield, Oliver, Nimmo, \& Habibi, 2008). Digital control systems receive inputs from sensors that measure the values of selected parameters within the system and adjust controllers within that system to achieve a desired system state. Advantages to the use of DCSs in place of analog control systems include:

- Less back-end wiring, because the sensor and control signals may be transmitted across a shared data bus instead of on dedicated data transmission lines as required on analog control systems;

- Increased functionality over analog control systems due to the availability of complex logic processing in the control circuitry;

- Increased reliability over analog control systems, in part through redundant circuitry that ensures system operation even when degraded conditions exist;

- Integration of disparate components, allowing functional integration of components across the plant;

- More cost-effective maintenance and modernizatin than their analog counterparts, simply due to the ready scalability and replaceability of the digital architecture and components; and

- Greater flexibility and access to a wider range of technologies in the operator interface.

From a human factors perspective, most of the advantages of DCSs center around the improvement to the HSI as compared to traditional analog controls. Digital control systems often have an interface consisting of soft controls within a video display unit, such as a multifunction display. Unlike analog systems, DCSs allow operators to use multiple input methods other than a manual manipulation of a button or dial.

Digital control systems can support keyboard and mouse inputs in addition to more advanced methods such as touch screen inputs. Another advantage of DCSs over analog components is the ease with which the system can be altered as new components are integrated into the system (Hollifield et al., 2008). This ease is, however, one of the sources of human factors shortcomings. As the system is modified, it is easy to add new features beyond those originally bundled with the system. Inconsistencies in the interface or outright human factors issues may develop as different design teams expand the DCS HSIs. A proliferation of HSI elements may occur, especially when there is a lack of a comprehensive graphical or HSI style guide. This report captures several DCS design recommendations that may be used in a standalone fashion or integrated into a comprehensive HSI style guide.

\subsection{Multifunction Displays}

The DCS displays used in nuclear power plant control rooms have strong similarities to the multifunction displays used in other industries, particularly when DCS displays are imbedded in existing analog control panels. Multifunction displays (MFDs) consist of a single surface or screen that receives digital signals from a variety of sources within a system, integrates the signals into meaningful representations of system component states, and displays that information in both common and separate reference frames (Mejdal, McCauley, and Beringer, 2001). MFDs are capable of displaying large amounts of data associated with multiple functions on a single surface by presenting the data in a layered format. Physical buttons located along the edge of the display originally supported navigation between layers and manipulation of system components within a layer (Francis and Reardon, 1997). With advances in technology, other input methods such as mouse, keyboard, and touch screen were added to the functionality of MFDs. MFDs have been used in a variety of industries including supervisory nuclear process control in the form of 
visual display units (VDU) (Hwang et al., 2009), but the aviation industry has been the primary realm for MFD development and implementation.

During the 1970s, the aviation industry took advantage of advancements in computer technologies and electronic display devices to integrate multifunction displays within aircraft cockpits. Aircraft cockpit instrument panels built in the 1960s and 1970s contained a multitude of analog gauges and controls that required pilots to spend a significant amount of heads-down time scanning many analog instrument panels (Francis and Reardon, 1997), typically color-coded round dials. The advent of digital controls allowed many flight parameters and functions to be displayed on a single flight-qualified display on an instrument panel and on heads-up displays that project the parameters and functions on a screen in the pilot's line of vision and on eyepieces in his or her helmet. MFDs concentrate the amount of space required for information presentation, which can reduce the amount of time that would be required to scan a larger physical space. To accomplish this, information must be presented in a hierarchical multi-menu manner with methods to navigate between the menus and select or manipulate objects within those menus. Good organization of the menus and the navigation capabilities between menus is critical in order to ensure the effectiveness of the MFD to convey information. Human factors are critical to the effective design of MFDs.

A large body of applied research has identified several human factors considerations for MFD design. The primary human factors consideration is the concept of breadth versus depth. Breadth refers to the number of items or selection options within each menu, and depth refers to the number of levels in the hierarchy (Paap and Cooke, 1997). As the depth of the hierarchy increases, the user must remember the correct selection choices in order to reach a desired menu. Conversely, as the breadth of the menu increases, the number of items that must be considered for a selection choice increases. Lee and MacGregor (1985) derived a formula to calculate the optimal breadth of 4 to 13 items per menu based on human response times, computer response times, and processing time per option. Deciding which hierarchical organization is more desirable depends on the goals of the system that the MFD will support. Systems with clear targets, such as the DCSs in NPP control rooms, benefit more from greater breadth since the larger number of items displayed convey more specificity than a small number of general selection options (Madjel, McCauley, and Berenger, 2001). Identifying the desired selection option takes less time with specific selection options than vague, general selection options. Expertise enhances the benefits provided by more breadth, since familiarity with the MFD improves the operators' mental representation of the hierarchical structure. Eye tracking analysis confirms that an experienced operator can immediately identify the desired selection option in a menu (Paap and Cooke, 1997). The operators' gaze immediately fixates on the desired selection option after interacting with the MFD. NPP operators receive considerable training, which affords them the necessary expertise for quickly identifying the desired menu choices in a DCS MFD. Grouping can further increase the optimal number of items in a menu from 4-13 up to 16 to 36.

\subsection{Chemical Volume Control System DCS}

The NPP under evaluation contains several DCSs. This evaluation focuses on the DCS for the chemical and volume control system (CVCS). Interviews with licensed nuclear reactor operators and systems engineers in conjunction with proprietary system description documentation were used to generate an overview of the functions and key components of the CVCS. The CVCS DCS consists of a combination of electrical and fluid process control components (see

Figure 1). The electrical and fluid components come from two different fields that use different graphical conventions. These competing conventions have not been fully reconciled, which makes the CVCS an important system to evaluate for potential human factors issues. 


\section{Chemical and Volume Control System}

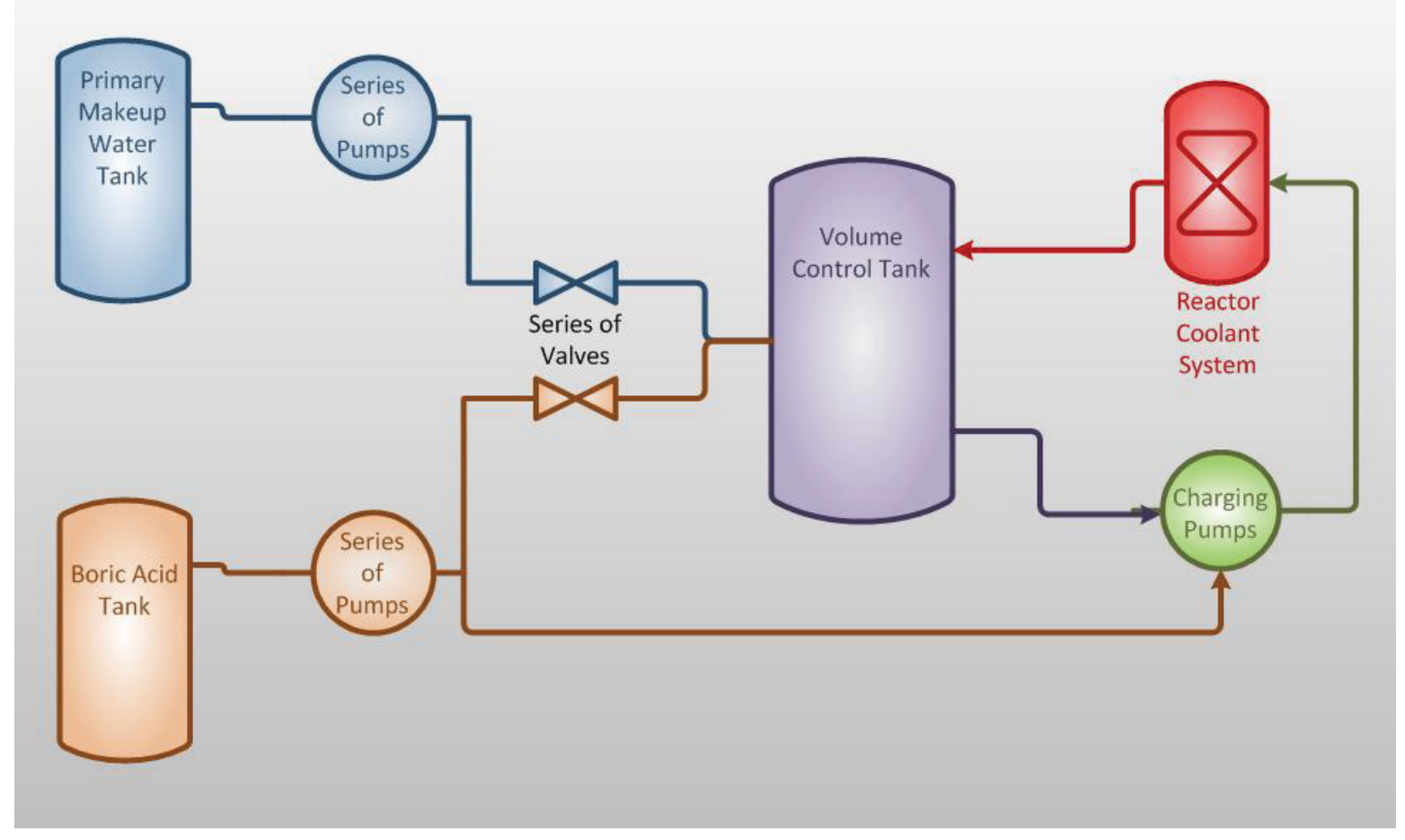

The CVCS is a fluid loop connected to the reactor coolant system whose purpose is to maintain the appropriate chemical composition and volume of the reactor coolant for a range of operating conditions. Most of the system is located outside containment.

The CVCS has a number of key components that allow it to maintain the chemical composition and volume of the reactor coolant. Letdown flow first passes through a pipe whose volume is sufficiently large to allow short-lived activation products, mainly Nitrogen-16 with its highly enerergetic gamma radiation, to decay to sufficiently low levels that most of the rest of the system can be located outside the containment. The regenerative heat exchanger then cools the letdown with flow being returned to the reactor coolant system, called charging flow. Parallel flow control valves control the letdown flow rate based on the pressurizer level. The pressure of the letdown is somewhat reduced in passing through the flow control valves and is further cooled to temperatures that the demineralizers can tolerate in the nonregenerative heat exchanger. Another parallel set of valves controls the pressure in the piping and nonregenerative heat exchanger downstream of the flow control valves. Pressure changes are damped by two accumulators to facilitate pressure control by the pressure controlling feedback control system. The cooled and depressurized flow of letdown is then routed to demineralizers, where impurities are removed or can be routed to the liquid radioactive waste storage.

The demineralizers discharge to the volume control tank (VCT) - a surge, degassing, and mixing volume that supplies treated water with the correct concentration of hydrogen and boric acid or demineralized water to the charging pumps. As a surge volume, it accommodates sudden changes in pressurizer level. 
The leakage rate from the reactor coolant system and non-isolable portions of connected systems is measured by the change in the level of the VCT with constant pressurizer level and reactor coolant system temperatures. Letdown is degassed, and radioactive and non-radioactive gasses are removed in the VCT. Hydrogen is added to the remaining water to control corrosion of the zirconium surfaces of the fuel pins.

The boron concentration of the water is adjusted by adding a mixture of boric acid and demineralized water. The VCT receives inputs from the primary make-up water (PMW) tank and the boric acid tank. The PMW contains treated demineralized water, and the boric acid tank contains highly concentrated boric acid. The boric acid tank and all outgoing lines are heated with electrical insulation to prevent the boron from precipitating. Boron concentrations in the reactor coolant are controlled by the flow rate of water from the PMW and boric acid from the boric acid tank. Operators control the boron concentration in the reactor coolant by adjusting the flow with valves located on the lines outflowing from each tank. The water and boric acid mix together at a junction known as the blending tee. The borated water then flows into the VCT, where it mixes with additional chemicals while awaiting recirculation through the reactor coolant system occurs.

The charging pumps receive fluid from the VCT and pressurize and return it to the reactor coolant system via the regenerative heat exchanger. Multiple (three) charging pumps reflect the safety critical function to provide fluid and inject boric acid at all operating reactor coolant system pressures. The charging pumps can draw power from diesel generators in the event of a grid power outage. Typically only one pump is running at a given time, though multiple pumps may be engaged simultaneously. In addition to receiving reactor coolant from the VCT, the charging pumps also connect to several redundant lines and sources of boric acid, which allow operators to inject boric acid directly into the reactor coolant during emergency operations. The high degree of redundancy demonstrates the safety critical nature of this system.

The CVCS displays and controls are physically located on the primary system panel in the MCR. The plant-specific DCS under investigation is a multifunction display operating in a Windows environment. Controlling the CVCS requires navigating between four windows and numerous pop-up windows. The boration dilution system window is the primary window with which the operator interacts. This primary window contains displays for the main components of the CVCS, which are the VCT, PMW tank and pumps, boric acid task and pumps, charging pumps, and primary valves. The displays for these components provide the operator with temperature, pressure, flow rates, and fill levels. System components are manipulated by selecting a button located near the components' symbol and label. The button opens a pop-up window with text entry fields and additional buttons. A navigation menu pop-up window allows the operator to examine other support windows. The indication window provides more detailed information about the components displayed on the main boration dilution system window. The status window contains a series of text entry boxes and buttons that allow the operator to take notes about the system status. The selected signals main window displays VCT levels and alternate boration flow.

The CVCS DCS under review has supported operators successfully for several years and continues to be refined. As part of a move toward HSI standardization, a usability evaluation was conducted on indevelopment DCS displays from the plant in order to determine a set of recommendations for the design of future displays. 


\section{HUMAN FACTORS BACKGROUND}

\subsection{Usability and the Human System Interface}

A number of NPPs have replaced analog control systems with digital control systems, including main control room (MCR) human system interfaces. In many cases, the digital controls directly mimic the former analog controls without special consideration of potential human factor issues. In other cases, new modes of interactivity are created by the DCS, potentially changing the operators' model of interactivity. Both cases require a thorough usability evaluation to ensure that the new human system interface is optimized to the reactor operators and conforms to human factors standards.

Fundamentally, the field of human factors aims to optimize the human system interface to improve safety, efficiency, and usability. Usability refers to the ease with which a user can acquire information from an interface and manipulate the interface to achieve a desired goal. Several techniques are used to evaluate the usability of an interface. A prominent technique is heuristic evaluation (also called an expert usability review), in which an interface is compared against a set of usability guidelines by expert evaluators. Within this framework, usability guidelines consist of a collection of design principles that help ensure good usability for an interface. Researchers and regulatory agencies have created a number of different guidelines to aid designers in making systems that support usability. Usability practitioners must select an appropriate set of guidelines that adequately address relevant design considerations for a particular system. Nielsen's usability heuristics (1994), Gerhardt-Powal's cognitive engineering principles (1996), NUREG-0700 by the U.S. NRC (2002), the International Standards Organization's (ISO) Standard 9241 (1998), and the International Society of Automation's (ISA) Standard 5.5 (1985) provide relevant guidelines for NPP MCR interfaces. Each will be discussed in detail in this chapter.

These sets of guidelines cover the majority of design considerations within NPP MCR interfaces. The guidelines vary in emphasis level of specificity. Nielsen's heuristic guidelines are the most general and can be applied to a wide range of applications including simple consumer product development and complex industrial systems development. Gerhardt-Powal's cognitive engineering principles are more specific guidelines that can be applied to human system interfaces involved with automation. The ISO 9421 standard contains specific perceptual and manipulation based guidelines for any application that makes use of visual display terminals. The U.S. NRC's NURGEG-0700 contains guidelines directly intended for NPP MCR development and updates. By using multiple sets of guidelines, a comprehensive set of human factors design considerations can be captured during a heuristic evaluation of a DCS. A brief description of some example guidance from each set of guidelines follows and provides an overview of what human factors aspects each can potentially capture during an evaluation.

Note that these guidelines and standards are not exhaustive but rather represent a realistic and relevant snapshot of current guidance that may be applied to evaluating DCSs in NPPs. More specific guidance, e.g., Management of Alarm Systems for the Process Industries, ANSI/ISA-18.2 (ISA, 2009), provides design recommendations applicable to a specific DCS function, while other general guidance, e.g., Information Display: Considerations for Designing Modern Computer-Based Display Systems, EPRI TR1002830 (Naser et al., 2003), prescribes a general design philosophy that underlies more detailed design guidance. Of course, guidelines and standards for design and evaluation should always be augmented by relevant, up-to-date research literature. In many cases, design and evaluation insights from the human factors research literature will predate by a decade or more their appearance in a guideline or standard. 


\subsection{Usability Guidelines}

\subsubsection{Nielsen's Usability Heuristics}

Nielsen's usability heuristics are by far the most popular in the usability field. A heuristic is simply a strategy to guide human problem solving. Here, usability heuristics are synonymous with design principles or guidelines, against which a human system interface may be evaluated. Table 1 shows Nielsen's usability guidelines for efficient and effective interfaces (1994). Nielsen's usability heuristics were intended to apply to a large number of interfaces. As such, some heuristics are of lesser importance than others for an evaluation of an NPP MCR.

Table 1. Nielsen's Usability Heuristics

\begin{tabular}{|l|l|}
\hline Simple and natural dialogue & $\begin{array}{l}\text { Dialogues should not contain information which is irrelevant or } \\
\text { rarely needed. Every extra unit of information in a dialogue } \\
\text { competes with the relevant units of information and diminishes their } \\
\text { relative visibility. All information should appear in a natural and } \\
\text { logical order. }\end{array}$ \\
\hline Speak the user's language & $\begin{array}{l}\text { The dialogue should be expressed clearly in words, phrases and } \\
\text { concepts familiar to the user, rather than in system-oriented terms. }\end{array}$ \\
\hline Minimize the user's memory & $\begin{array}{l}\text { The user should not have to remember information from one part of } \\
\text { the dialogue to another. Instructions for use of the system should be } \\
\text { visible or easily retrievable whenever appropriate. }\end{array}$ \\
\hline Consistency & $\begin{array}{l}\text { Users should not have to wonder whether different words, } \\
\text { situations, or actions mean the same thing. }\end{array}$ \\
\hline Feedback & $\begin{array}{l}\text { The system should always keep users informed about what is going } \\
\text { on, through appropriate feedback within reasonable time. }\end{array}$ \\
\hline Clearly marked exits & $\begin{array}{l}\text { Users often choose system functions by mistake and will need a } \\
\text { clearly marked "emergency exit" to leave the unwanted state } \\
\text { without having to go through an extended dialogue. }\end{array}$ \\
\hline Shortcuts & $\begin{array}{l}\text { Accelerators-unseen by the novice user-may often speed up the } \\
\text { interaction for the expert user such that the system can cater to } \\
\text { both inexperienced and experienced users. }\end{array}$ \\
\hline Good error messages & $\begin{array}{l}\text { They should be expressed in plain language (no codes), precisely } \\
\text { indicate the problem, and constructively suggest a solution. }\end{array}$ \\
\hline Prevent errors & $\begin{array}{l}\text { Even better than good error messages is careful design that } \\
\text { prevents a problem from occurring in the first place. }\end{array}$ \\
\hline Help and documentation & $\begin{array}{l}\text { Even though it is better if the system can be used without } \\
\text { documentation, it may be necessary to provide help and } \\
\text { documentation. Any such information should be easy to search, be } \\
\text { focused on the user's task, list concrete steps to be carried out, and } \\
\text { not be too large. }\end{array}$ \\
\hline
\end{tabular}

An example of a few of the more relevant guidelines provides a good depiction of how these heuristics can be applied to NPP MCRs. One relevant heuristic or guideline states that the interface should provide the visibility of the system status within a reasonable time so that the operator knows what is happening. A failure to adhere to this guideline was a fundamental causal factor of the Three Mile Island Accident (Kemeny, 1979). A light designed to indicate the position of the pilot operated relief valve did not directly indicate the valve position. Instead, the light indicated that a signal had been sent to the solenoid controlling the valve. Due to the lack of visibility of the stuck open valve position, the operators were unable to diagnose the problem in time to prevent core meltdown.

A second relevant guideline states that the interface for the system should match the real world by using language and conventions that are familiar to the operator (Nielsen, 1994). NPPs follow this guideline by accurately labeling indicators and controls with the name of the component they are associated with. Furthermore, the indicator or control identification number is displayed below the label. The operators' familiarity with the language and conventions might simply be a result of industry practice over the last 30 years. The current conventions may be adequate, but an evaluation of individual screens within the 
MCR may reveal more intuitive labels that support NPP operators integrating system components into mental models during training.

A third relevant guideline states that systems should have consistency and follow established standards (Nielsen, 1994). This guideline is arguably the most important guideline for an MCR due to the sheer size and complexity of the instrument panels. With large amounts of data that must be displayed to the operator, a consistent manner for presenting that information is crucial in preventing confusion. Maintaining consistency is difficult within the MCR because multiple vendors design different components.

\subsubsection{Gerhardt-Powal's Cognitive Engineering Principles}

Gerhardt-Powal's cognitive engineering principles can be seen in Table 2 (1996). These principles emphasize automation of unwanted workload and integration of data for higher-level summation.

Gehardt-Powal's principles attempt to shift the burden of information integration from the operator to the automation. These principles become particularly relevant to NPPs as they begin to upgrade their existing analog systems to digital systems that could integrate large amounts of data.

Table 2. Gerhard-Powal's Cognitive Engineering Principles

\begin{tabular}{|l|l|}
\hline Automate unwanted workload & $\begin{array}{l}\text { Eliminate mental calculations, estimations, comparisons, and unnecessary } \\
\text { thinking to free cognitive resources for high-level tasks }\end{array}$ \\
\hline Reduce uncertainty & $\begin{array}{l}\text { Display data in a manner that is clear and obvious to reduce decision time and } \\
\text { error }\end{array}$ \\
\hline Fuse data & $\begin{array}{l}\text { Bring together lower level data into a higher level summation to reduce cognitive } \\
\text { load }\end{array}$ \\
\hline $\begin{array}{l}\text { Present new information with } \\
\text { meaningful aids to interpretation }\end{array}$ & $\begin{array}{l}\text { New information should be presented within familiar frameworks (e.g., schemas, } \\
\text { metaphors, everyday terms) so that information is easier to absorb }\end{array}$ \\
\hline $\begin{array}{l}\text { Use names that are conceptually } \\
\text { related to function }\end{array}$ & $\begin{array}{l}\text { Display names and labels should be context-dependent, which will improve recall } \\
\text { and recognition }\end{array}$ \\
\hline $\begin{array}{l}\text { Group data in consistently, } \\
\text { meaningful ways }\end{array}$ & $\begin{array}{l}\text { Within a screen, data should be logically grouped; across screens, it should be } \\
\text { consistently grouped. This will decrease search time }\end{array}$ \\
\hline Limit data driven tasks & $\begin{array}{l}\text { Use color and graphics, for example, to reduce the time spent assimilating raw } \\
\text { data }\end{array}$ \\
\hline $\begin{array}{l}\text { Include in the displays only that } \\
\text { information needed by the operator } \\
\text { at a given time }\end{array}$ & $\begin{array}{l}\text { Exclude extraneous information that is not relevant to current tasks so that the } \\
\text { user can focus attention on critical data }\end{array}$ \\
\hline Provide multiple coding of data & $\begin{array}{l}\text { The system should provide data in varying formats and/or levels of detail in order } \\
\text { to promote cognitive flexibility and satisfy user preferences }\end{array}$ \\
\hline Practice judicious redundancy & $\begin{array}{l}\text { To maintain consistency it is sometimes necessary to include more information } \\
\text { than may be needed at a given time }\end{array}$ \\
\hline
\end{tabular}

One example guideline states that data-driven tasks should be limited by reducing the time spent assimilating raw data with the appropriate use of color and graphics. There are many ways to integrate data. For example, an NPP MCR contains clusters of indicators pertaining to specific components. Each indicator displays a single system parameter state, but the operator needs to integrate the overall pattern created by each single parameter. A multivariate data visualization technique known as a star plot could aid operators in understanding complex relationships between parameters (Chambers et al., 1983). The spokes of the star represent individual parameters and the tips of the spokes are connected with lines. As parameters change, the length of the spokes change and the overall shape of the star changes. The shape of the star serves as an emergent feature that can quickly inform the operator about the component's state.

Another relevant cognitive engineering principle states that data should be grouped consistently and in a meaningful way to reduce search time (Gehardt-Powal, 1996). NPPs originally failed to adhere to this grouping principle as evidenced by the Three Mile Island Accident (Kemeny, 1979). A temperature sensor located downstream of the stuck open pilot operated relief valve could have alerted the operators 
that the valve was open. Unfortunately, the indicator for this temperature sensor was not grouped with the indicators associated with the pilot operated relief valve, and the operators failed to notice it.

\subsection{Standards}

\subsubsection{ISO Standard 9241}

ISO Standard 9241 provides ergonomic guidelines for video display units in an office environment (ISO, 1998). This standard is not specific to NPPs, but the video display units within NPPs function in the same manner as a video display unit in an office setting. Since this standard pertains to video display units at large, only NPP MCR relevant sections of ISO Standard 9241 were used in this evaluation. Some of the relevant sections include dialogue principles, presentation of information, and menu dialogues. ISO Standard 9241 defines dialogue as the interaction between a user and a system to achieve a particular goal.

The dialogue principle section (ISO 9241-10) identifies seven important principles for video display unit design, which include:

- Suitability for the task,

- Self-descriptiveness,

- Controllability,

- Conformity with user expectations,

- Error tolerance,

- Suitability for individualization, and

- Suitability for learning.

For example, the suitability for the task principle contains several specific recommendations, one of which is ISO 9241-10 3.2, which states the dialogue should support the user when performing recurrent tasks. This recommendation is particularly relevant to NPP monitoring, since operators must complete numerous repetitive tasks.

The presentation of information section contains three groups of guidelines: organization of information, graphical objects, and coding techniques. These categories are relevant to NPP monitoring since the large amount of information presented must be organized, integrated into graphical representations, and coded. The menu dialogue is arranged with smaller subgroups such as menu structure, grouping options within a menu, rapid navigation, and option selection and execution.

\subsubsection{ISA Standard 5.5}

ISA Standard 5.5, Graphics Symbols for Process Displays, provides guidelines for designing graphs and flow diagrams used in process control interfaces (ISA, 1985). This standard contains three sections that cover the different design aspects of symbols used in graphs and flow diagrams. Section 3.1.1 contains thirteen general guidelines for the use of symbols. For example, 3.1.1 number four states graphic symbols should be arranged to depict the spatial relationship or process flows in a consistent manner. Guideline number six from this section states arrows overlaid on process lines may be used to indicate process flow. Though this additional information may improve performance, a practitioner should take careful consideration for preventing any confusion between the flow indicator arrows and the valves that are located on the process lines in an NPP. 
Section 3.1.2 contains guidelines for using color in the display. Several guidelines from this section are relevant to both digital and analog controls in NPPs due to the extensive use of color coding. Guideline 3.1.2 number seven states colors should not be used to indicate quantitative value. For example, a dynamic value should always remain the same color. Guideline 3.1.2 number eight recommends designers create a color plan containing all the color associations for each process. Each process may have a different meaning for a color, which does not conform to human factors principles. Table 3 contains an example color plan.

Table 3. ISA Color Plan Example

\begin{tabular}{|c|c|c|}
\hline Color & Generic meaning & Element association \\
\hline Black & Background & \\
\hline Red & Emergency & $\begin{array}{l}\text { A) Stop } \\
\text { B) Highest Priority Alarm } \\
\text { C) Closed } \\
\text { D) Off }\end{array}$ \\
\hline Yellow & Caution & $\begin{array}{l}\text { A) Abnormal Condition } \\
\text { B) Second Priority Alarm }\end{array}$ \\
\hline Green & Safe & $\begin{array}{l}\text { A) Normal Operation } \\
\text { B) Start } \\
\text { C) Open } \\
\text { D) On }\end{array}$ \\
\hline Cyan (Light Blue) & Static \& Significant & $\begin{array}{l}\text { A) Process Equipment in Service } \\
\text { B) Major Labels }\end{array}$ \\
\hline Blue & Nonessential & $\begin{array}{l}\text { A) Standby Process Equipment } \\
\text { B) Labels, Tags, etc. }\end{array}$ \\
\hline Magenta (Purple) & Radiation & $\begin{array}{l}\text { A) Radiation Alarms } \\
\text { B) Questionable Values }\end{array}$ \\
\hline White & Dynamic Data & $\begin{array}{l}\text { A) Measurements \& State Information } \\
\text { B) System Messages } \\
\text { C) Trend } \\
\text { D) Active Sequential Step }\end{array}$ \\
\hline
\end{tabular}

The last section, 3.3 Structure of Symbols, contains guidelines for the physical appearance of different symbols used in graphs and flow diagrams. The guidelines include symbol names, abbreviations, descriptions, and an image of the symbol. Nearly all symbols in these guidelines are located on DCS displays in NPPs.

Note that the ISA has set up a committee to develop a new human machine interface standard (SP101), which is anticipated to encompass and eventually replace ISA Standard 5.5. At the time the present report was being written, a final version of the new standard was not available for review.

\subsubsection{U.S. NRC NUREG-0700}

NUREG-0700 (Rev. 2), Human-System Interface Review Guidelines, was designed specifically to address human factors issues in NPP MCRs (U.S. NRC, 2002). The primary advantage of NUREG-0700 as a standard is that it provides the most specific guidelines for NPP interfaces. NUREG-0700 is a comprehensive list of hundreds of guidelines with very specific recommendations. For example, NUREG-0700 1.3.1-6 states that the stroke of the letter must be at least one-twelfth of the letter height. 
Beyond such specific guidance, NUREG-0700 also includes general recommendations. For example, NUREG-0700 1.3.2-1 states that abbreviations should be avoided unless the abbreviations are commonplace.

The guidelines from NUREG-0700 are highly specific to the primarily analog control rooms that were current in 2002. New digital control systems have considerations that are not covered by the current guidelines in NUREG-0700. For example, some DCSs receive inputs through a touch screen interface, which is simply not covered by NUREG-0700. A third revision to NUREG-0700 is currently in preparation, which will address some of this lack of coverage for digital systems.

Furthermore, some recommendations in NUREG-0700 include antiquated and inefficient industrial practices. For example, NUREG-0700, Section 1.3.8-5, states that colors should be selected to match industry practices. The recommendation includes a table of acceptable colors (see Table 4), but several of the acceptable colors have contradictory meanings. The color red, which is used in many places throughout NPPs, has six different meanings in NUREG-0700. As with the other standards, the majority of the guidelines provide sound recommendations. However, as seen, standards do contain guidelines that violate human factors principles depicted in Nielsen's usability heuristics and Gerhardt-Powal's cognitive engineering principles.

Table 4. Acceptable Color Associations and Characteristics from NUREG-0700

\begin{tabular}{|c|c|c|c|}
\hline Color & Associated Meanings & $\begin{array}{l}\text { Attention } \\
\text {-Getting } \\
\text { Value }\end{array}$ & $\begin{array}{c}\text { Contrasts Well } \\
\text { With }\end{array}$ \\
\hline Red & $\begin{array}{l}\text { Unsafe } \\
\text { Danger } \\
\text { Alarm state } \\
\text { Hot } \\
\text { Open/flowing }{ }^{1} \\
\text { Closed/stopped }^{1}\end{array}$ & Good & White \\
\hline Yellow & $\begin{array}{l}\text { Hazard } \\
\text { Caution } \\
\text { Abnormal State } \\
\text { Oil }\end{array}$ & Good & $\begin{array}{l}\text { Black } \\
\text { Dark Blue }\end{array}$ \\
\hline Green & $\begin{array}{l}\text { Safe } \\
\text { Satisfactory } \\
\text { Normal state } \text { Open/flowing }^{1} \\
\text { Closed/stopped }^{1}\end{array}$ & Poor & White \\
\hline $\begin{array}{l}\text { Light blue } \\
\text { (cyan) }\end{array}$ & $\begin{array}{l}\text { Advisory } \\
\text { Aerated water } \\
\text { Cool }\end{array}$ & Poor & Black \\
\hline Dark Blue & $\begin{array}{l}\text { Advisory } \\
\text { Untreated water }\end{array}$ & Poor & White \\
\hline Magenta $^{2}$ & Alarm state & Good & White \\
\hline White & $\begin{array}{l}\text { Advisory } \\
\text { Steam }\end{array}$ & Poor & $\begin{array}{l}\text { Green } \\
\text { Black } \\
\text { Red } \\
\text { Dark blue } \\
\text { Magenta }\end{array}$ \\
\hline Black & Background & Poor & $\begin{array}{l}\text { White } \\
\text { Light blue } \\
\text { Yellow }\end{array}$ \\
\hline \multicolumn{4}{|c|}{$\begin{array}{l}1 \text { Meanings associated with red and green colors differ, depending on past experience. } \\
\text { Personnel with previous fossil fuel plant experience typically associate an open/flowing } \\
\text { state with red and a closed/stop state with green, but reverse associations typically exist } \\
\text { for personnel with previous Navy experience. }\end{array}$} \\
\hline${ }^{2}$ Magenta or & $\mathrm{w}$ is the nuclear industry sta & lard for radiat & aution. \\
\hline
\end{tabular}




\subsection{Use of Guidelines and Standards}

In the context of nuclear power, the overarching goal of these guidelines and standards for is to aid researchers and practitioners in identifying the optimal way of representing process control information to operators. Effective presentation of information provides operators with higher levels of situation awareness (SA). In the context of an NPP MCRs, SA refers to the operators' understanding of the nuclear process control system state and the degree to which that understanding reflects the true state of the system. Situation awareness is a prerequisite to the judgment and decision making required for supervisory monitoring and control of the dynamic and complex processes within an NPP (Patrick et al., 2006).

Lau et al. identified a number of SA related properties inherent to advanced NPPs with fully digital HSIs (2011). NPPs consist of the causal and continuous process of converting thermal energy into electrical energy. NPP MCRs contain abstract scientific principle representations associated with the energy conversion process. NPPs consist of integrated large scale systems, each system comprised of many components, some of which will fail and must be replaced while minimizing costs due to plant maintenance shutdowns. Fully digital HSIs may also rely on a large amount of automation that controls processes with complex algorithms. The automation may fail during certain abnormal situations, which requires the operators to manually adjust system parameters. The highly integrated nature of an NPP means that components are tightly coupled such that manipulating one component will affect other components, which makes the system complex. NPP process running state changes, random system perturbations, and control responses occur relatively slowly in comparison to other process control domains, which further adds to the complexity of the system, since the plant dynamics often result in delayed rather than instant feedback.

As mentioned previously, NPPs strive to operate continuously even while conducting system tests such as Technical Specification Surveillances. The system tests change the context of indicator levels in a meaningful way, which must be accounted for while monitoring and controlling NPP processes. Some surveillances require manipulating large valves that sometimes fail to operate as required, leading to the need to quickly and accurately identify malfunctions and respond accordingly. These properties of NPPs drive the manner in which operators interact with the process from the MCR. The majority of operators' interactions with the NPP processes consist of monitoring the MCR panels, with occasional actions to adjust processes.

Due the complexity and large volume of context dependent information displayed in an NPP MCR, the indicators and controls must be designed carefully to support operator SA acquisition. Ensuring good SA acquisition is a central consideration for NPP MCR upgrades including upgrades to existing DCSs. Usability heuristics, guidelines, and standards provide human factors principles that support the operator acquiring SA. The degree of the HSI's adherence to these usability heuristics, guidelines, and standards provides a measure of potential operator SA. 


\section{EVALUATION METHOD}

\subsection{General Approach}

The DCS was evaluated with two main approaches. First, the researchers consulted with two nuclear engineers and a software developer from the NPP containing the DCS under investigation. These subject matter experts (SMEs) provided background information concerning the functionality of the CVCS, the DCS interface, and ways in which the operators interact with the DCS. The DCS was then evaluated against usability heuristics, standards, and regulatory guidance to identify and document any issues that would lead to degraded performance. A series of interviews was conducted with other SMEs external to the NPP to provide additional feedback. The SMEs used were three process control engineers and two software developers. The SMEs were first provided with the background information on the functionality of each screen in the DCS. Then the SMEs exercised a think-aloud protocol (Duncker, 1945; Ericsson and Simon, 1993) in which the SMEs were asked to verbalize their thoughts while viewing the DCS screens. Several human factors researchers observed the SMEs during each interview to document the feedback provided by the SMEs. Issues where the HMI could be improved and positive feedback where the SMEs liked aspects of the HMI were then catalogued and classified with the same heuristics and standards used in the first approach. The feedback identified in the two main approaches was then integrated to form a comprehensive evaluation. The goal of the evaluation was to identify aspects of the HSI for the DCS where design guidance would help standardize and improve future DCS development.

\subsection{Heuristic, Standards, and Regulatory Guidance Evaluation}

The evaluation identified areas for improvement. An area for improvement was defined as any usability issue that violates any of Nielsen's usability heuristics, Gerhardt-Powal's cognitive engineering principles, NUREG-0700, ISA Standard 5.5, or ISO Standard 9241. The evaluation also included issues that could not clearly be categorized as a violation of any one heuristic, principle, or standard guideline. Note that the identified potential usability issues did not imply operator performance deficits. No operator performance metrics were collected in this evaluation.

\subsection{Subject Matter Expert Interviews}

\subsubsection{DCS Examples}

The SMEs were presented with screenshots taken from the DCS under investigation. Due to the plant proprietary nature of these screenshots, they are not included in this report. The plant-specific CVCS DCS consists of four windows and 21 pop-up windows, which are displayed on a single touchscreen on the primary energy panel in the MCR. Of the four main windows, the operators primarily interact with the control window. From each of the main windows, an operator selects a navigation button. This action displays a pop-up window containing a menu of navigation buttons corresponding to each main window. Adjusting process control components is accomplished in the same manner. A button is located near a component, which when selected will display a pop-up window containing controls for that component. All screenshots included one of the main windows with a combination of pop-up windows with which the operator would normally interact. The screenshots were displayed on a large LCD monitor during the evaluation. 


\subsubsection{Subject Matter Experts}

Five SMEs were interviewed during the evaluation. Three of the SMEs were process control engineers, and two of the SMEs were software engineers. The two groups of SMEs were selected for two reasons. First, the process control SMEs were selected to augment the heuristic evaluation. They have valuable knowledge about process control and have used DCSs in that context. Two of the process control SMEs had nuclear power backgrounds, while the third process control expert had fuel and chemical control system experience. The second cohort of SMEs was comprised of two software engineers, who represent a novel sample of engineers with little to no knowledge of nuclear power generation. The lack of knowledge about specific control systems and processes to generate electricity from nuclear power allowed for input from graphical user interface developers who could compare DCS designs against current best practices in consumer interfaces.

\subsubsection{Procedure}

During each interview SMEs were positioned in front of a large LCD monitor that displayed the DCS screen shots. A researcher provided high-level information concerning the role of the CVCS and an overview of the primary components that are monitored and manipulated by the interface. A think-aloud technique was used in which the SMEs were asked to verbalize their thoughts while examining the screen shots. The SMEs were also encouraged to ask questions that were answered by the researchers. The SMEs were informed that they could move through the screens at their own pace with the use of a mouse or keyboard arrows. When a novel screen was encountered, a researcher provided a brief description of the functionality of that particular screen. The SMEs were also asked to use the mouse to highlight the components as they examined them, so that observers could record comments and questions in relation to specific components.

\subsubsection{Observer Recording}

A minimum of two researchers acted as observers during the interviews. Usability related comments and questions were recorded on forms containing a reduced size depiction of the display. The form allowed the observers quickly to capture the thoughts of the SMEs without having to describe any of the components. For example, if the SME was reviewing a pop-up window for the VCT, the corresponding notetaking form featured a printout of the exact display the SME viewed on screen. The observers could simply annotate this printout by circling the relevant items discussed by the SME. The observers recorded all instances of the following:

- Discoverability of the interface elements by the SMEs,

- SME questions about the functionality of the interface where the interface did not readily afford its interactivity or function,

- Elements of the interface that led to confusion in the SMEs,

- Recommendations by the SME regarding alternative ways to depict information in the DCS, and

- Positive or negative comments by the SME regarding the interface elements.

The purpose of having multiple observers was to ensure a reasonably complete capture of comments and issues by the SMEs. The notes from these multiple observers were aggregated for each SME who walked through the DCS screenshots. 


\subsection{Analysis}

The heuristic evaluation and SME interviews were tabulated and yielded a total of 167 usability items, primarily in the form of usability issues. The potential issues reflect multiple reports of some of the same potential usability issues and not 167 unique issues. The usability issues were analyzed with consideration for the importance of the issue on potential operator performance and the frequency that the issue was reported by the SMEs. The importance of the issue on operator performance was assessed by evaluating the issues against Nielsen's usability heuristics, Gerhardt-Powal's cognitive engineering principles, NUREG-0700 guidelines, ISA Standard 5.5, and ISO Standard 9241. The most important usability issues were then categorized into conceptual groups for the purpose of reporting the findings. Recommendations were created to improve the compliance of the interface with good human factors principles outlined in the heuristics, guidelines, and standards. Static prototypes were then created to demonstrate the implementation of the recommendations both in isolation (i.e., individual indicators and controls) and collectively in a fully redesigned DCS display.

A representative sample of issues is provided in Table 5. Potential usability issues are considered plant proprietary and are not reported in detailed fashion here. Instead, in the next chapter, design recommendations are reported. These design recommendations were derived through careful review by human factors researchers of potential issues against usability guidance and standards. The design recommendations also incorporate design suggestions provided by the SMEs. As previously noted, the usability issues did not imply operator performance deficiencies. The issues represent opportunities for incremental improvements on a DCS that is already being used successfully by operators. The purpose of the design recommendations is to provide standardization for future DCS displays.

Table 5. Example Evaluation Resulting from Usability Analysis

\begin{tabular}{|c|c|c|c|c|c|c|c|c|}
\hline \multicolumn{9}{|c|}{ CVCS Heuristic Evaluation } \\
\hline Issue Number & SME & Observer & \begin{tabular}{|c|} 
Screen \\
Number
\end{tabular} & Screen Title & Screen Element & $\begin{array}{c}\text { Heuristic(s) } \\
\text { Violated }\end{array}$ & Issue(s) & Solution(s) \\
\hline 33 & P3 & 02 & 30012 & $\begin{array}{l}\text { Boration Dilution } \\
\text { System / Indication }\end{array}$ & Tank box borders & GP10, N4 & $\begin{array}{l}\text { The thick brown border for boration is } \\
\text { redundant with the (brighter) orange } \\
\text { border around selected objects. The } \\
\text { colors are different but potentially } \\
\text { confusing. }\end{array}$ & Remove orange/brown color redundancy. \\
\hline 34 & P3 & 02 & 30011 & $\begin{array}{l}\text { Letdown Flow } \\
\text { Control Valve }\end{array}$ & Valve buttons & GP2, N2 & $\begin{array}{l}\text { When a button is selected, it has a white } \\
\text { fill rather than the gray of an unselected } \\
\text { button. Only the fill color differentiates an } \\
\text { "in service" pump from an "out of serivce" } \\
\text { pump, creating ambiguity. }\end{array}$ & $\begin{array}{l}\text { A better indicator to show that a pump is } \\
\text { "in service" would be to manipulate the } \\
\text { button's shadow to create an impression } \\
\text { of depression; of the button being } \\
\text { depressed. A border or more familiar color } \\
\text { change might also be effective. }\end{array}$ \\
\hline 35 & P3 & 02 & 30011 & $\begin{array}{l}\text { Boration Dilution } \\
\text { System / Status }\end{array}$ & Save buttons & GP2, GP5 & $\begin{array}{l}\text { Save buttons at the bottom of each lon } \\
\text { Exchanger Status column have ambiguous } \\
\text { functions. (Is the information saved to a } \\
\text { log? If so, is that log availible?) }\end{array}$ & $\begin{array}{l}\text { The function of the save buttons should be } \\
\text { more obvious, and a log to contain the } \\
\text { saved data should exist, if that is the } \\
\text { purpose of the buttons. }\end{array}$ \\
\hline 36 & P3 & 02 & 30006 & VCT & $\begin{array}{l}\text { Red background to } \\
\text { percent indicator }\end{array}$ & N1, N9 & $\begin{array}{l}\text { Red may be being used to communicate a } \\
\text { status other than an alarm. When this area } \\
\text { is alarming, more information on the } \\
\text { problem should be readily availible. }\end{array}$ & $\begin{array}{l}\text { Red should only be used to communicate } \\
\text { an alarm. A click or hover function should } \\
\text { be included to pull up more information } \\
\text { about the alarm, if it is one. There should } \\
\text { also be a function to acknowledge the } \\
\text { alarm. }\end{array}$ \\
\hline 37 & P3 & 02 & 31009 & $\begin{array}{l}\text { W2 Graphics } \\
\text { Window }\end{array}$ & Pop-up window & N1 & $\begin{array}{l}\text { The pop-up window blocks system } \\
\text { information. }\end{array}$ & $\begin{array}{l}\text { A small pane could be set aside for } \\
\text { dialogues, rather than having pop-ups } \\
\text { cover potentially important information. }\end{array}$ \\
\hline
\end{tabular}

LEGEND: N = Nielsen (1994) Heuristic Number (see Table 1, this report); GP = Gehardt-Powal (1996) Principle Number (see Table 2, this report) 


\section{ISSUES AND RECOMMENDATIONS}

The issues and recommendations contained within this report should be interpreted in the context of a representative collection of DCS displays and not as a reflection of any deficiencies of the plant-specific DCS under review. Developers of DCSs at NPPs have tended to design the systems to closely resemble their former analog components in order to minimize additional licensing and abide by regulations. In other cases, DCS standards developed outside the context of NPPs have been adopted. The translation of original analog components into digital representations now presents an ideal opportunity for a human factors review to determine if the digital displays can be further optimized beyond their analog origin. A number of usability recommendations that could potentially improve performance were identified. Potential DCS usability issues and recommendations are outlined in Table 6 and detailed in subsequent sections of this chapter. Throughout this chapter, the images that are presented represent new DCS displays (except where indicated) that were generated expressly to illustrate application of the design recommendations.

Table 6. Usability Issues and Design Recommendations

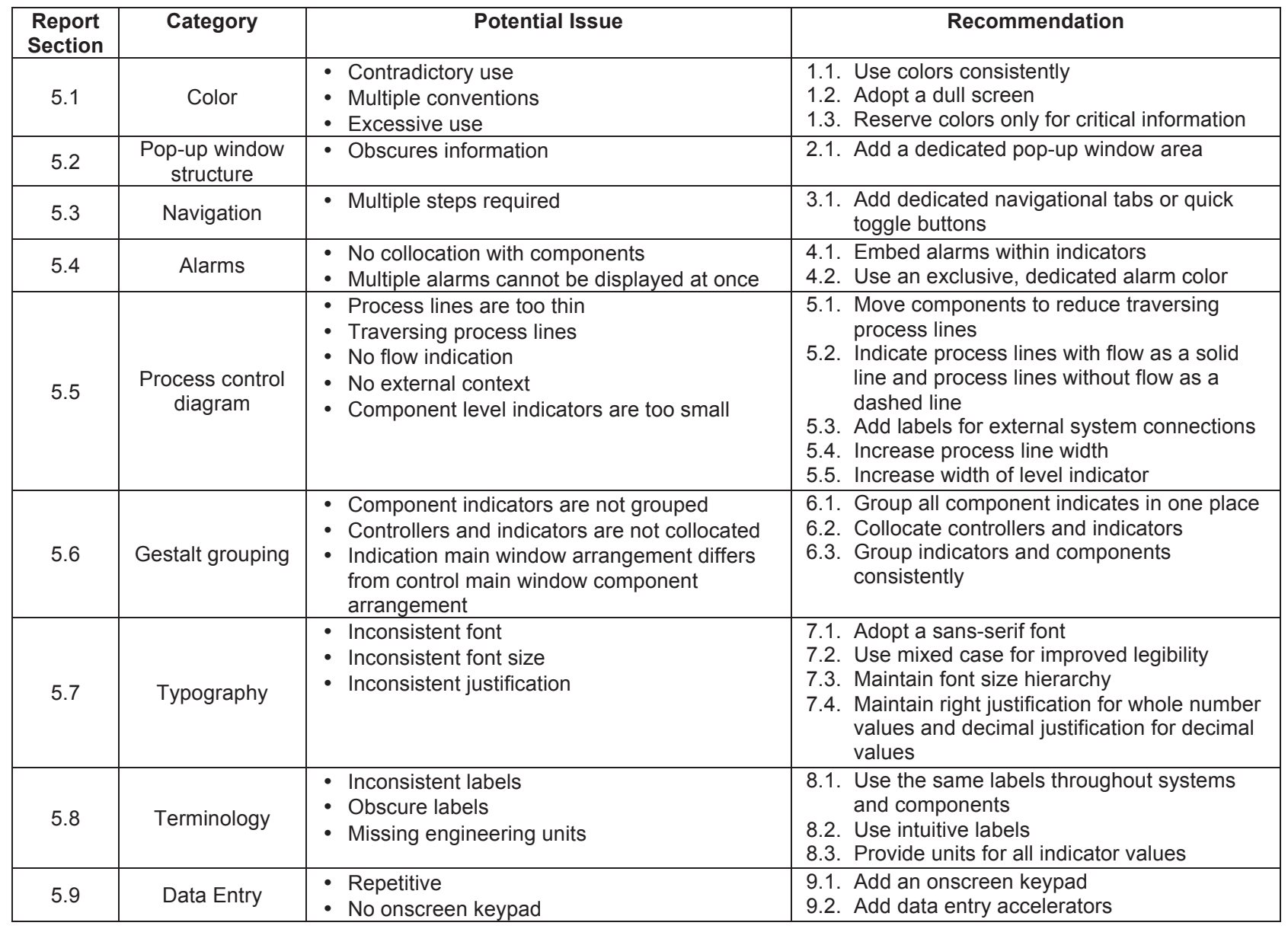




\subsection{Color}

The most prominent category of issues is color. A multitude of colors are used in the DCS displays, sometimes in conflicting ways. For example, the color red and green take on several different meanings depending on the application. NUREG-0700 and ISO Standard 9241 provide guidelines that include conflicting uses for these two colors as can be seen in Table 3 and Table 4 (U.S. NRC, 2002; ISO, 1998). By allowing for the conflicting use of red and green, Nielsen's "consistency" heuristic and GerhardtPowal's "reduce uncertainty" principle are violated (Nielsen, 1994; Gerhardt-Powal, 1996). The primary conflicting uses of these colors occur with the depiction of electrically driven pumps vs. flow valves in the DCS interface. The color green is used to indicate a pump is off, and the color red is used to indicate a pump is on or energized. In contrast, the color green is used to indicate the valve is open, and the color red is used to indicate the valve is closed. The green and red color associations are reversed between the pumps and the valves. Red and green are also used with different meanings across the DCS displays. Green is used as a safe state for certain indicator levels, while red is used as an alarm state for those same indicators. Green is used as an indicator for a selected button in the pop-up windows controlling the pumps. The boron tank and PMW flow controllers use green with yet another meaning on the downward pointing arrow button, which is used to adjust the flow controller's output. Red is used as an indicator for a selected mode button in the mode selector pop-up window. Red is also used for a specific alarm involving the number of charging pumps active during alternate boration.

\section{Recommendation 1.1: Use colors consistently}

Inconsistent use is not the only issue related to color. The number of colors and amount of color used cause some potential usability issues. ISA 5.5 guidelines for color use state that the number of colors should be limited to the minimum number required for the displays objective (ISA, 1985). The guidelines warn against irrelevant color use that leads to noise and negates the utility of color-coding. The ISA 5.5 guidelines recommend using four colors for most applications. The large number of colors used in the main control and indication windows reduces the utility of color-coding in general. Furthermore, the operator must remember the significance of each color while interacting with the interface. ISO 9241 recommends that no more than six colors should be used, but if more than six have to be used, a legend should be included to provide the operator with the correct associations (ISO, 1998). This DCS under review contains enough unused screen space that a legend could be included. However, the distraction from using many colors simply cannot be prevented with a legend.

The colored elements compete with each other and with other achromatic window elements for the operators' attention. The number and amount of colors reduces the ability for any one color to draw the attention of the operators. In line with Gerhardt-Powal's "only information relevant to an operator should be included" principle, the interface should adopt a dull or greyscale screen (Gerhardt-Powal, 1996). The dull screen would eliminate the majority of the colors from the interface. Only critical elements would use color to provide salient cues that effectively draw the operators' attention.

\section{Recommendation 1.2: Adopt a dull screen}

Several changes to the existing DCS are required to adopt a dull screen. The valves would change in color, but for the sake of redundancy, the valves' shape would also change in compliance with standards from ISA 5.5 (ISA, 1985). To indicate the open state of a valve, the valve symbol is solid green, as seen in Figure 2. To indicate a closed valve, the valve symbol consists of a grey outline of the valve, in contrast to the original red indication. The same convention can be applied to the pump indicators. A grey outlined pump indicates a pump in the off state and a solid green pump indicates a pump in the energized state. Green and grey are used to represent slightly different meanings, since solid green represents 
energized and open while grey represents off and closed. Despite multiple meanings for green and grey, this color convention improves upon the red-green color delineation, because it reduces the overall amount of color on the screen, and it eliminates two uses of the color red. Note that the fluid-matched color values (gold for boron and blue for water) are retained in this DCS display element for easy identification by operators. However, a dotted line is added to indicate closed flow paths, offering a redundant cue to operators beyond the color-coding of the valves and pumps.

Figure 2. Reduced Color Examples for and Valves (a) and Pumps (b and c), Where Grey Replaces Red in Original DCS Screens

(a)

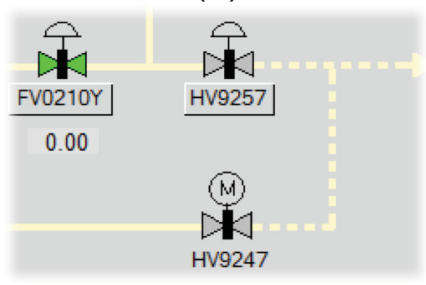

(b)

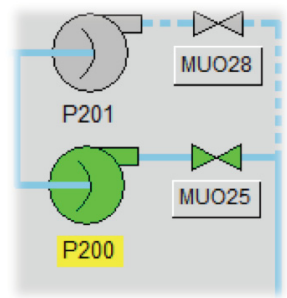

(c)

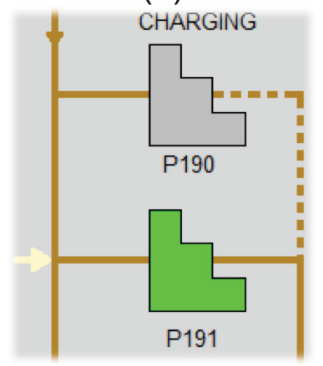

By removing overlapping uses of the color red, red can now be reserved solely for alarms. Figure 3 provides an example of the salience of red in the HSI when dedicated to alarms. Alarms are of paramount importance in a safety critical system such as an NPP, and therefore it is imperative that the color red has only one association. Furthermore, red is culturally associated with danger; so, using it in this fashion adds perceptual advantages for alarms, helping them stand out to operators when displayed as designated on-screen annunciators or when embedded in the process diagram within the DCS. Note that the specific use of red only for alarms would require operator retraining to prevent confusion with existing learned color schemes.

Figure 3. Example of Dedicated Red Alarm Color in the DCS

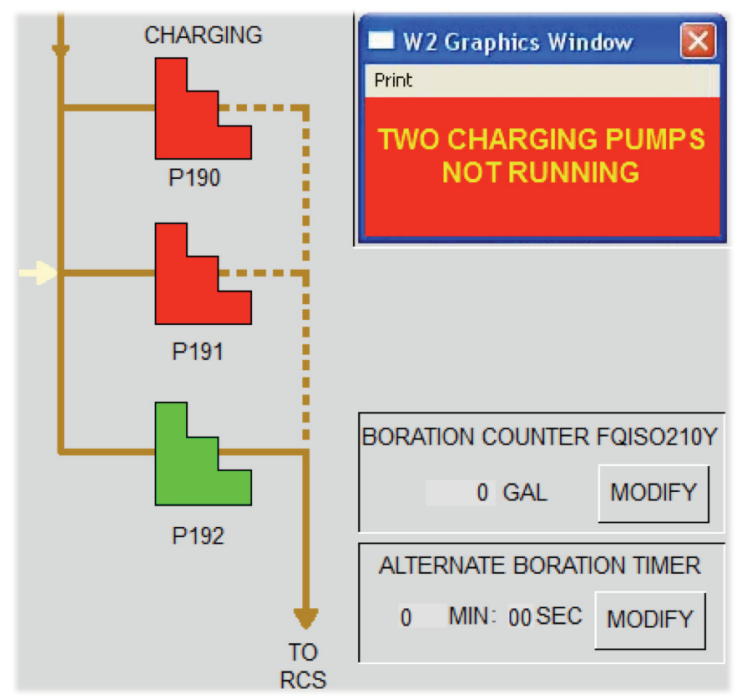

Recommendation 1.3: Reserve colors only for critical information 
The indication main window also requires changes for the adoption of a dull screen. The current system uses a guide next to each indicator to provide context dependent information dynamically (see Figure 4(a) for an example from the current DCS). Green and red represent normal and alarm levels for a particular indicator. The space between the green and red represents off normal levels for a particular indicator. In order to maintain consistent color use, green can be eliminated from the indicator guide. In the proposed dull screen version of the indicator level (see Figure 4(b)), grey is used to indicate normal, yellow is used to indicate off normal, and red is used to indicate alarm indicator levels. The blue bar used to indicate the level in the current DCS in Figure 4(a) is changed to a shade of grey in order reduce the number of colors used. Additionally, the colors used are dulled such that they do not attract attention as much as the component colors on the control main window. However, when an indicator falls within the alarm range, such as in Figure 4(b), the color red is made more vivid in order to draw attention to the alarmed indication and the grey arrow beside the indicator is also highlighted red.

Figure 4. Example Current Level Indicator (a) and Revised Level Indicator (b)

(a)

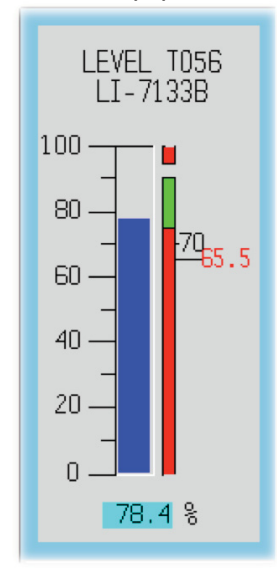

(b)

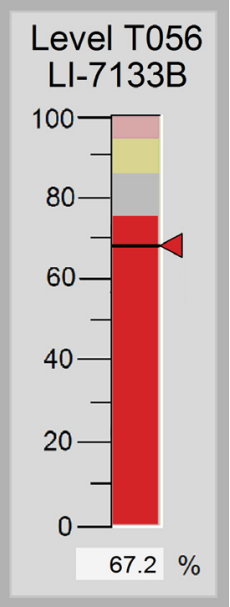

All dialogues contained within the pop-up windows would also require some changes in order to adopt a dull screen. Instead of yellow and green to indicate the selected button in the pump controls window (see Figure 5(a)) and red indicating the selected mode button in the mode selector pop-up window (see Figure 5(b)), a three dimensional coding scheme can be used. A black line along the bottom and right side of the button as proposed in Figure 5(c) creates the illusion of a shadow below the button, which makes the button appear to be raised. Place the black line along the left edge and top of the button creates the illusion of a shadow above the button, which makes the button appear to be depressed. The operator can still determine the state of the buttons within pop-up modes, but the use of color throughout the pop-up windows is reduced. 
Figure 5. Current Colorful Pump Control Indication (a), Current Pop-Up Mode Selector (b), and New Dull Screen Mode Selector (c)

(a)

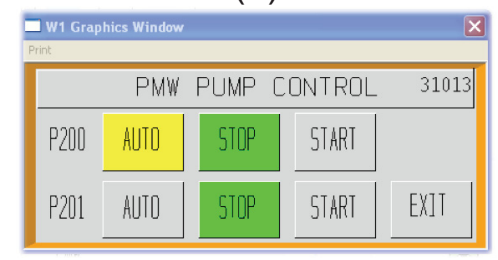

(b)

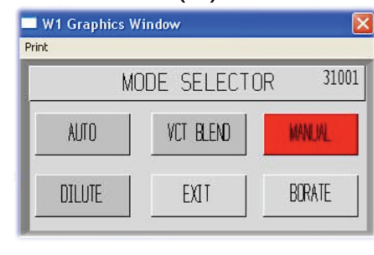

(c)

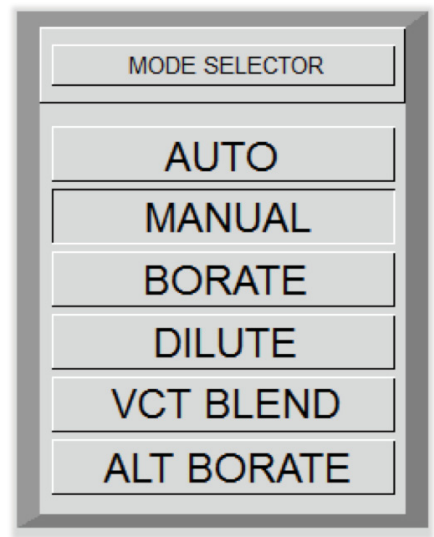

\subsection{Pop-Up Window Structure}

The pop-up window structure of the current DCS interface causes information located on the control main window to be occluded. The designers took care to position the pop-up location so that the pop-up window does not occlude its associated display component. However, the pop-up window still occludes other areas of the control main window. The visibility of the system is reduced, which violates Nielsen's "feedback" and "minimize the user's working memory" usability heuristics (Nielsen, 1994). To prevent information from being occluded, a dedicated pop-up window pane should be included in each of the main displays. This is a shift away from the pop-up structure in that any active component will display its controls only in this designated area. In addition to preventing any information from being occluded, the designated area provides a consistent display area for all component controls. As the operators interact with the system, they will quickly learn to look for the controls in the designated area. However, it is possible for operators to overlook the expanded view pane of the display. The system may employ modest means to attract the operator to the expanded view pane of the display; however, such attentiongetting schemes should minimize distracting features like bright colors or flashing, whenever possible.

\section{Recommendation 2.1: Add a dedicated pop-up window area}

Figure 6 shows an example of a dedicated pane for alerts, pop-up windows, and alarms in the upper right of the DCS display. This area can accommodate several simultaneous system dialogs, overcoming a potential limitation of the current DCS whereby only one active dialog window can be displayed at a time. Note that the alarm dialog shown earlier in Figure 3 would also be displayed in this area of the display. 
Figure 6. Designated Expanded View Pane for Pop-Up Windows and Alarms in Top Right of DCS Window

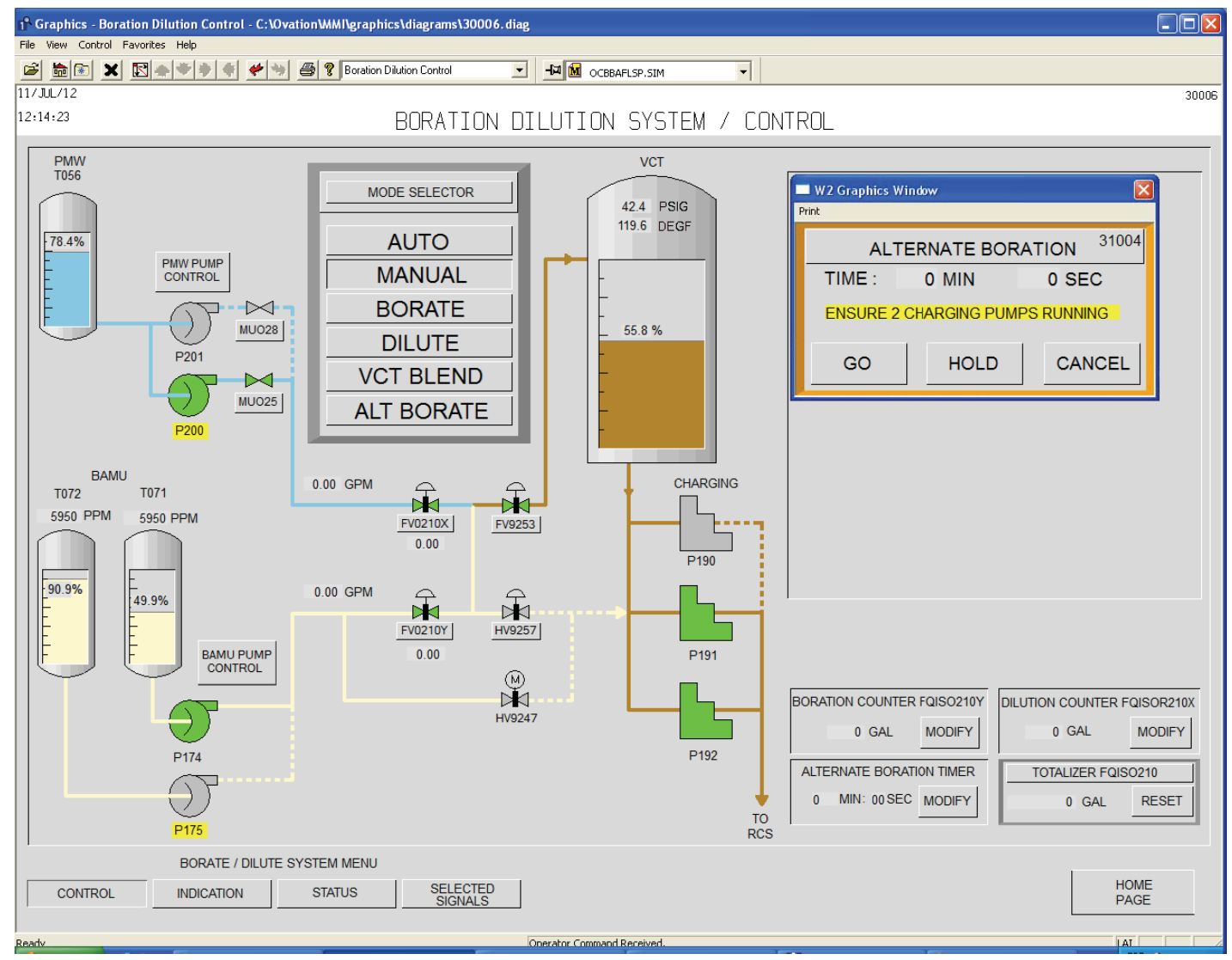

\subsection{Navigation}

Navigating between the main windows requires several steps. The process begins by selecting the Borate/Dilute Graphic Menu button. This causes a pop-up window with buttons for the four main windows to appear. The operator must select another button to activate the menu buttons, before any navigation buttons can be selected. The repetitive process violates Gerhardt-Powal's "limit data driven tasks" principle (Gerhardt-Powal, 1996). Nielsen's "feedback" and "minimize the user's working memory" usability heuristics are also violated, since a significant portion of the screen is occluded by the pop-up window. When navigating to another main window, the occluded information must be maintained in working memory longer, which could lead to errors. Fortunately, a solution exists to improve the usability of the navigation menu. Instead of using a pop-up window to display the navigation buttons, a dedicated navigation display could be used. This can be accomplished by utilizing the bottom bar of the display (see Figure 6 above), which is not used in the current DCS. Due to the ample screen space within this bottom bar, the menu option buttons could be added without interfering with any other parts of the interface. The operators could now navigate to different main windows with a single selection. An activation button or a pop-up window containing confirm and cancel buttons would prevent accidental navigation if so desired. However, providing quick, one-step buttons to jump between screens would effectively eliminate the need to have a confirmation dialog when switching between screens. Ensuring the operator could easily back out of a step is less burdensome than requiring confirmation when switching screens. This toggle functionality has long been included in multifunction displays and has proven to be a quick and safe way to go between pre-defined display windows. 
Recommendation 3.1: Add dedicated navigational tabs or quick toggle buttons

\subsection{Alarms}

The current CVCS DCS contains one alarm with the text, "TWO CHARGING PUMPS NOT RUNNING", in yellow on a bright red background. The alarm is displayed in the top right corner of the interface next to the main window title area. The alarm is associated with the state of the charging pumps involved with the alternate boration mode of operation. The charging pumps are located along the bottom portion of the control main window, yet the alarm is located at the top of the window. The lack of collocation places additional effort on the operator to search for the charging pumps, which violates Gerhardt-Powal's "fuse data and group data in consistently, meaningful ways" principle (Gerhardt-Powal, 1996). Furthermore, the current display only supports the presentation of one alarm within the title area of the main windows. To the best of the authors' knowledge, only one alarm is associated with the CVCS DCS system. If multiple alarms are integrated into this system or if the DCS is expanded to other systems, then the ability to display only a single alarm could become a significant limitation.

\section{Recommendation 4.1: Embed alarms within indicators}

Both the location and lack of support for multiple alarms can be addressed by a simple recommendation, in which the alarms are embedded within components. Embedding alarms within the components they are associated with draws the operators' attention directly toward the component while also allowing the display of multiple alarms simultaneously. The method for indicating an alarm could include enabling the component to blink and an appropriately color coded text display adjacent to the component. As depicted earlier in Figure 3 and Figure 4(b), the use of red as a dedicated alarm color allows the DCS to embed alarms in the graphical display of the system. In addition, as was shown in Figure 3, in is possible to provide both on-screen annunciator windows and embedded alarms.

\section{Recommendation 4.2: Use an exclusive, dedicated alarm color}

\subsection{Process Control Diagram}

The process control diagram in the current DCS depicts components and process lines that map the process flow between the components. The CVCS interfaces with other systems within the NPP. The current DCS displays the inputs to the CVCS from the PMW and the boric acid tanks, but the connections to the reactor coolant system are not shown. The operator must infer that those connections are present when interacting with the interface. The indication main window contains indicators that pertain to these connections, but these connections are never graphically represented on the control main window. Nielsen's "feedback" heuristic and Gerhardt-Powal's "reduce uncertainty" principle are violated by not providing the contextual information in the display (Nielsen, 1994; Gerhardt-Powal, 1996).

A partial representation of the current DCS process control diagram can be found in Figure 7. In addition to other issues mentioned in this chapter, a number of diagram specific issues were identified by the SMEs, including:

- Thin lines,

- Crisscrossing process lines,

- Indicators for PMW flow located adjacent to the boric acid tank, and

- Lack of clear exit path from the charging pumps. 
Figure 7. Existing DCS Process Control Diagram

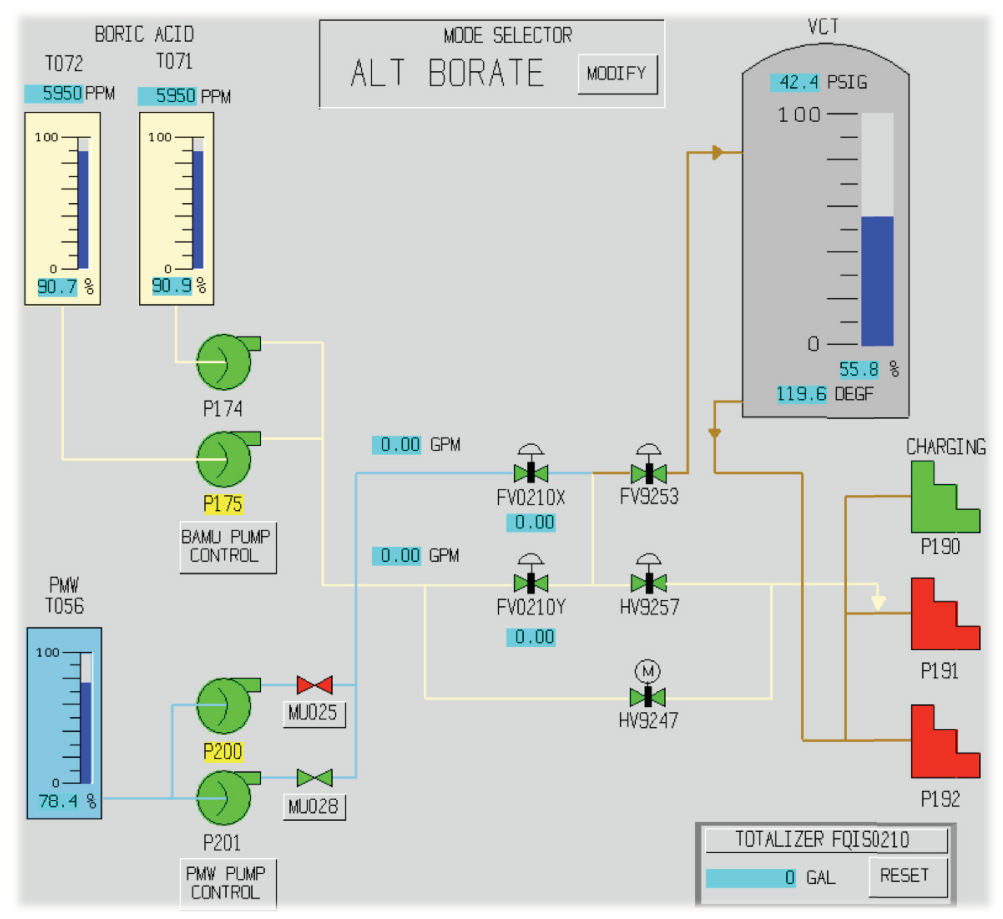

In the current DCS, the process lines within the process diagram effectively show the connections between components and the direction of flow, but they do not provide information about active flow through the process line. The operator must trace the process line and examine each valve position to determine if active flow is present in a certain portion of the flow path. Active flow through a line should be readily apparent to the operator in order to reduce mental effort in accordance with Gerhardt-Powal's "fuse data" principle (Gerhardt-Powal, 1996). Displaying active flow can be achieved by coding process lines without flow as dashed lines and process lines with flow as solid lines. The more salient solid line depicting active flow serves as an emergent feature that can quickly provide an operator with the overall flow pattern in the CVCS. For visibility, the process lines should be displayed with greater width. The lines in the current system are thin, which reduces their visibility and demands greater visual acuity when tracing the process lines. An example of more discernible process lines with active flow indication can be found in the prototype control main window shown in Figure 8.

Recommendation 5.1: Move components to reduce traversing process lines

Recommendation 5.2: Indicate process lines with flow as a solid line and process lines without flow as a dashed line 
Figure 8. Revised Control Main Window

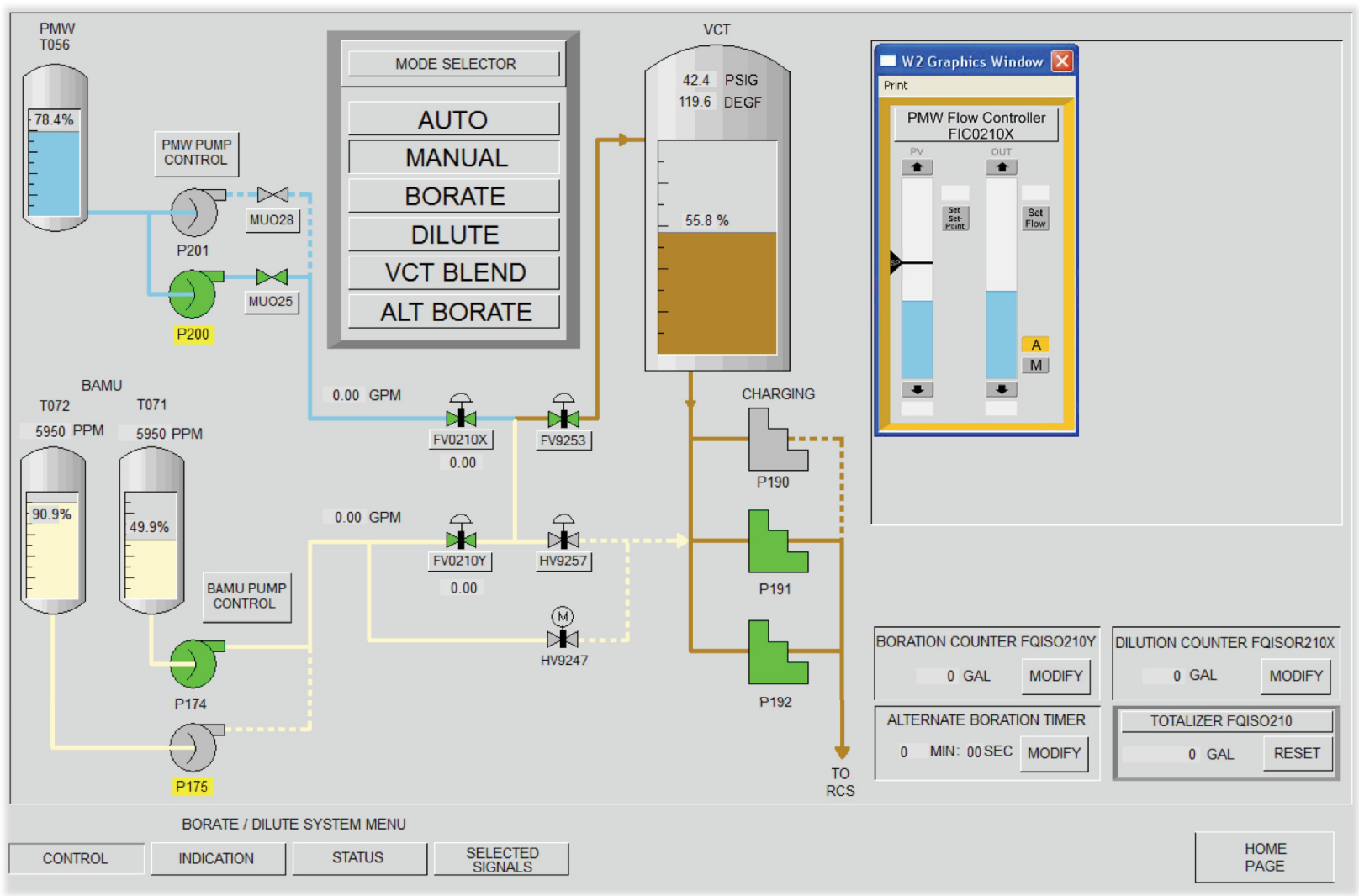

In addition to more discernible process lines, the connections between the CVCS and reactor coolant system (RCS) should be visible. More generally speaking, the connections between on-screen systems and off-screen upstream or downstream systems should be shown. Operators can infer that the charging pumps connect to the RCS fairly easily, but the process diagram in the current DCS in Figure 7 does not show the outgoing connections to the RCS. For consistency, both the charging pump and incoming connections to the reactor coolant system information should be depicted with process lines flowing into and out of the CVCS. The process lines should be clearly labeled to convey that they interface with the RCS, as shown in Figure 8.

\section{Recommendation 5.3: Add labels for external system connections}

A potential source of confusion regarding the current DCS results from the primary makeup water and boric acid process line flow paths crossing over each other, which violates Nielsen's "feedback" heuristic and Gerhardt-Powal's "reduce uncertainty" principle (Nielsen, 1994; Gerhardt-Powal, 1996). Presumably, the crossover occurs because the redundant boric acid process lines would be confusing if they were restricted to the space between the boric acid tank and the VCT. Instead the designers elected to depict the boric acid lines along the bottom, which necessitated a process line crossover (see Figure 7). The issue is compounded by two flow indicators that can easily be incorrectly associated with the opposite process line due to the initial crossover of the process lines. Due to the complex nature of the CVCS, it is not possible to entirely prevent the process lines from traversing. However, redesigning the flow paths of the process lines can reduce the amount of crossover. Switching the locations of the boric acid tank and PMW unit eliminates the initial confusing cross over. Locating the boric acid tank on the bottom, as shown in 
Figure 8, allows the redundant boric acid process lines to have a direct path to the charging pumps. The redundant boric acid process line's connection with the charging pumps should also be changed to reflect the true physical configuration.

\section{Recommendation 5.4: Increase process line width}

A number of components within the process diagram, such as the VCT, have level indicators embedded within their display. The graphical depiction of the level aids the operator in determining the volume filled percentage of the tank. The volume filled percentage value located at the bottom of the indicators in the current DCS (see Figure 7) provides the operator with an additional representation of the tank level. The level is an important parameter as evidenced by multiple representations provided by the interface designers. The level indicator and volume filled percentage must, however, compete with the other values embedded within the component's display. The saliency of the level indicator can be increased by extending the width of the indicator to the width of the tank component display. The volume filled percentage value would be yoked to the level indicator so that it always remains in close proximity to its associated level. Yoking the volume filled percentage to the level indictor also allows for the removal of the vertical axis hatch marks, which reduces the amount of clutter on the display (see Figure 8).

\section{Recommendation 5.5: Increase width of level indicator}

Note that the axis hatch marks may provide important cues and are recommended by many human factors standards. As depicted previously in Figure 4(b), the saliency of level indicators can be greatly enhanced by providing tick marks and acceptable level bands. The precise impact of tick marks and level bands on operator performance remains undetermined. It is not the purpose of Figure 8 to suggest that such supplemental indications should be omitted from level indicators. Figure 8 simply presents one of many possible design alternatives, here in the context of an overall process control diagram in the DCS.

\subsection{Gestalt Grouping}

Gestalt is a German word referring to the complete form of an object or how the object hangs together. Gestalt is used within human factors to refer to the logical grouping of interface elements. A good interface gestalt is one in which different elements are properly synthesized to allow the target user to understand the meaning of those elements readily. Gestalt grouping principles are therefore especially applicable for complex HSIs like those found in control rooms.

Many of the components on the existing control main window have multiple indicators associated with them. For example, the VCT component has a level, temperature, and pressure indicator. These indicators are located on the displayed component, which helps strengthen the perception that they all relate to the same component. However, they are not grouped together in one location on the displayed component, which increases the visual search time required to assess the overall component's condition. The lack of grouping violates Nielsen's "simple and natural dialogue" heuristic and Gerhardt-Powal's "group data in consistently, meaningful ways" principle (Nielsen, 1994; Gerhardt-Powal, 1996). To reduce the operators' search time for relevant data, all the indicators should be grouped together at the top of the displayed component.

\section{Recommendation 6.1: Group all component indicates in one place}

Another issue with grouping concerns manipulated components (i.e., controls) and the indicators associated with them. For example, the boric acid and PMW flow controls are used to adjust the flow of boric acid and water coming from the boric acid tank and PMW, respectively. In the current DCS, the 
boric acid tank and PMW flow controls are located on the right side of the control main window, while the indicators displaying the levels of the liquids in the boric acid tank and PMW are located on the left side of the screen. The lack of grouping reduces the perception that flow controllers and the level indicators are related to a common task. Furthermore, the visual search time increases when manipulating the flow controllers, since the operators' gaze must switch between the flow controllers and the indicators. Collocating the flow controllers and the indicators would reduce the search time and strengthen the perception that they are related to a common task.

\section{Recommendation 6.2: Collocate controllers and indicators}

The indication main window provides supplemental detailed information about the components located on the control main window. The indicators are grouped based on the components that they represent. The interface effectively groups and color codes the indicators, but the location of the indicator groups and indicators within groups is not consistent in the existing DCS display. For example, the PMW and letdown indicator groups are arranged with the flow indicator on the rightmost edge of the group, but the charging indicator group is arranged with the flow indicator on the leftmost edge of the group. The inconsistency violates Nielsen's "simple and natural dialogue" heuristic and Gerhardt-Powal's "reduce uncertainty" principle (Nielsen, 1994; Gerhardt-Powal, 1996). The flow indicator for the charging group should be positioned at the rightmost edge to maintain consistency, which potentially leads to better operator performance. The locations of the groups on the indication main window are also inconsistent with the location of their associated components on the control main window. The indicator groups should be positioned in the same configuration as the components on the control main window. An example of a gestalt grouped indicator panel is seen in Figure 9.

Figure 9. Revised Indication Main Window

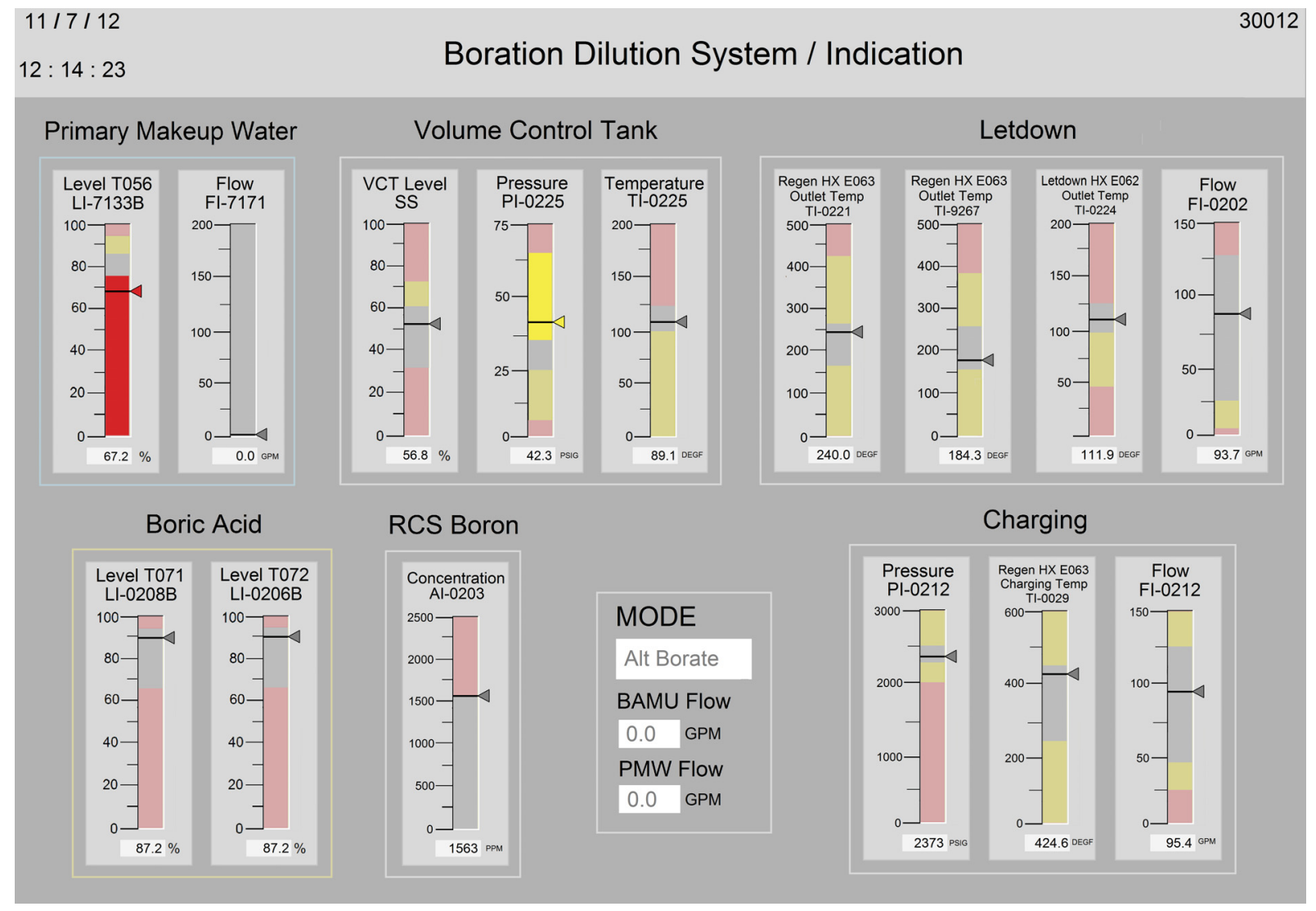


Recommendation 6.3: Group indicators and components consistently

On this sample redesigned indication screen, indicators that relate to a common process are grouped together in boxes. Data on the exact indicator level is consistently displayed at the bottom of each indicator. The groups are spatially consistent with the location of components on the main screen. The configuration is the same as on the main boration menu. Within the groups, indicators have a consistent order. Flow indicators are consistently on the right of the groups. Level indicators sit on the left. Clear group labels aid in locating the desired indicators. In addition, limited use of color minimizes operator distraction in navigating through information on the display.

\subsection{Typography}

Throughout the main windows and pop-up windows in the current DCS, several different fonts and a mixture of upper and lower cases are used for window titles, component labels, and indicator labels. Additionally, the stroke width of the fonts is very thin, which leads to reduced legibility. NUREG-0700 contains a guideline stating the stroke of the font should be at least one-twelfth the height of each character to ensure good legibility (U.S. NRC, 2002). A single font with a sufficient stroke should be adopted. Arial, a common Sans Serif font, is a good candidate for this digital interface, since there is support for Arial possessing good legibility when presented on a digital screen (Sheedy et al., 2005). All titles and labels should use a case convention in which whole words include lowercase letters to improve word recognition (Lavidor and Ellis, 2001; Sheedy et al., 2005). Acronyms should use only uppercase characters. This case convention also aids the operator in discriminating between acronym and word titles and labels. Figure 9 provides a clear example of these typographic conventions. Figure 8 provides an example of all uppercase labels. These labels follow the convention of the existing analog control panels in the control room, which features uppercase labels. As NUREG-0700, Section 1.3.1-1, points out, use of uppercase may be appropriate for drawing attention to specific text such as labels.

Recommendation 7.1: Adopt a sans-serif font

Recommendation 7.2: Use mixed case for improved legibility

There are several sizes of text used for the titles and labels in the current DCS. Space constraints mandate the use of multiple font sizes in order to fit titles and labels on certain components. However, consistent sizes should be used when possible. For example, the current alternate boration timer (see Figure 10) uses a different size font for the displayed time and the modify button associated with the timer. There is ample space for both to be displayed with a consistently sized font.

Recommendation 7.3: Maintain font size hierarchy 
Figure 10. Alternate Boration Time Window in Current DCS

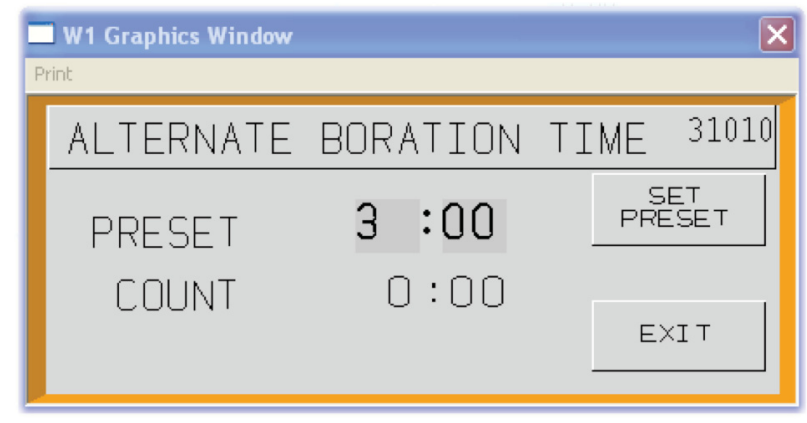

The justification (e.g., typographic alignment) for numeric entry fields is inconsistent in the current DCS. The majority of the entry fields are right justified, but the alternate boration timer pop-up window contains a preset time entry field that is left justified (see Figure 10). The inconsistent justification violates ISO 9241 on information presentation standards. ISO 9241 states numeric information without a decimal should be right justified, while numeric information with a decimal should be aligned to the decimal (ISO, 1998). The interface should adopt this numeric presentation convention throughout the interface.

\section{Recommendation 7.4: Maintain right justification for whole number values and decimal} justification for decimal values

\subsection{Terminology}

The primary issue with the terminology used in the current DCS interface concerns consistency. There are numerous labels and titles that are used inconsistently throughout the system. For example, the boration dilution display represented in Figure 7 is actually denoted four different ways:

- Boration Dilution Control from a dropdown menu at the top of the DCS window,

- Boration Dilution System / Control on the window title bar,

- Borate/Dilute Graphic Menu as a navigation button at the bottom of the display, and

- Control as a button on the Boration Dilution Naviation Menu

This inconsistency of labeling can, in some cases, lead to operator confusion when navigating between DCS windows in the display.

Recommendation 8.1: Use the same labels throughout systems and components

Some components, such as the boric acid tank, are labeled with shortened versions of component names throughout the interface. The boric tank unit is labeled as boric acid, boric acid tank, boric acid makeup unit, and $B A M U$ within different areas of the display. The use of acronyms vs. complete names is also inconsistent. For example, the boric acid tank level indicators are labeled with the words boric acid spelled out while the primary makeup water unit is labeled with the acronym $P M W$. The display contains enough room that the label could be spelled out with words for both labels or abbreviated consistently according to operator preference. Consistent labels should be used throughout the display. 
Recommendation 8.2: Use intuitive labels

In addition to inconsistent terminology, some values in the current DCS displays are missing engineering units. For example, the primary flow valves that are critical for the functionality of the CVCS do not have engineering units for the values displayed below them. The operators are forced to recall the engineering units from memory when interacting with this interface. All engineering units should be displayed next to their associated values throughout the interface.

\section{Recommendation 8.3: Provide units for all indicator values}

\subsection{Data Entry}

The current status main window contains 45 numeric entry fields in which dates, times, and boron concentrations can be manually input and logged for use within the DCS. Operators must select each field individually and then enter the numeric value with a physical keypad resting on the lower portion of the control panel to which the DCS screen is mounted. Because of the need to input many data fields with a wide separation of display and input device, entering data fields is time consuming and laborious. The process of entering data is a violation of Gerhardt-Powal's "automate unwanted work" principle (Gerhardt-Powal, 1996). To reduce the repetitiveness of data entry, the operators should have a method to move between the entry fields without having to touch or select each field. Adding two buttons to this display would allow the operators to move serially through the entry fields quickly. The ability to select a particular entry field is still intact, but the alternative movement buttons provide flexibility within the controls. Additionally, hot keys such as the Tab button on the keyboard should be active, to allow operators to toggle between fields without having to alternate between keypad and mouse or touch screen.

Another issue with the status main window pertains to entering numeric values. If the operator is not a touch typist, entering the values requires the operators' gaze to shift from the DCS interface to the keypad and then back to the entry field to verify the correct numbers were input. The possibility for errors is increased by not being able to see in real time the key that was pressed and the value that was registered, which violates Nielsen's "prevent errors" heuristic (Nielsen, 1994). Two solutions can reduce the possibility for errors with this portion of the interface. Adding an on-screen numeric keypad will allow the operators to keep their gaze on the display, minimizing potential errors resulting from the visual saccade between the screen and the keypad. In addition to an on-screen numeric keypad, an accelerator can be used to input the time and dates. For example, a pop-up window with the current calendar would allow the operators to select the correct date while eliminating the separate keypad entry method (see Figure 11).

Recommendation 9.1: Add an onscreen keypad

Recommendation 9.2: Add data entry accelerators 
Figure 11. Date Entry Accelerator Calendar

\begin{tabular}{|c|c|c|c|c|c|c|c|c|}
\hline Note: & \multirow{2}{*}{ 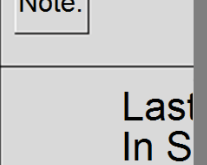 } & \multicolumn{7}{|c|}{ March, 2012} \\
\hline $\begin{array}{l}\text { Last Time } \\
\text { In Service }\end{array}$ & & \multicolumn{7}{|c|}{ Su Mo Tu We Th Fr Sa } \\
\hline Date: $3 / 15 / 12$ & \multirow{3}{*}{$\begin{array}{l}\text { Date: } 3 \text { l } \\
\text { Time: } 12 \text { : } \\
\text { RCS Boro }\end{array}$} & & & & & 1 & 2 & 3 \\
\hline Time: $12: 00$ & & 4 & 5 & 6 & 7 & 8 & 9 & 10 \\
\hline RCS Boron PPM: & & 11 & 12 & 13 & 14 & 15 & 16 & 17 \\
\hline 997 & & 18 & 19 & 20 & 21 & 22 & 23 & 24 \\
\hline Save & Savi & 25 & 26 & 27 & 28 & 29 & 30 & 31 \\
\hline
\end{tabular}




\section{DISCUSSION}

The nine design recommendations presented in the previous chapter are intuitive aspects of interface design. Yet, in practice, they may prove easy to overlook without a design checklist. The design recommendations were generated in response to observed usability issues in an existing DCS system. The purpose of highlighting these issues is not to suggest the current DCS is inadequate or in any way compromises the operators' ability to operate the plant. Rather, these recommendations represent opportunities to rectify minor usability issues and prevent their recurrence in further DCS development efforts. Ultimately, the nine design recommendations serve as the starting point for a standardized digital style guide. It is anticipated that additional design recommendations will be gathered in subsequent systematic evaluations of DCS displays across multiple plants. These design recommendations will be aggregated into a concise but comprehensive DCS style guide, including checklists to aid designers in implementing effective DCS interfaces. The style guide and corresponding checklists may serve as supplemental guidance to the information already contained in the guidelines and standards mentioned in this report.

In addition to evaluating a wider sample of current and in-development DCSs at NPPs, it is important that operator-in-the-loop studies be performed to validate DCSs:

- First, current guidelines and standards for interface development are culled from multiple sources, many of which are not nuclear in nature. While a good interface for a workstation in an office environment should translate into a good interface for a DCS, the typical purpose of the office workstation (e.g., word processing) is not the same as process control. Not all guidance and standards are equally applicable or have been fully validated for nuclear control room operations.

- Moreover, the use of expert or heuristic usability evaluations is prone to the experience and biases of the subject matter experts performing the evaluation (Kirmani and Rajasekaran, 2007) and may not capture actual user performance. The consequences of any individual usability issue in terms of decrements to operator performance are not well established, nor is it possible objectively to prioritize or risk-rank the issues using the heuristic method.

- As Boring et al. (2005) have noted, expert evaluation techniques have been optimized for consumer software applications, but there may be difficulties in extrapolating those approaches to safety-critical domains. Absent validation of heuristic methods for nuclear applications, they remain an effective first-pass approach to identifying issues, but they are not exhaustive.

- Finally, heuristic evaluation has not in practice proved a good method for pre-post design testing. In other words, the heuristic evaluation conducted in this study was effective in identifying initial usability issues, but it is challenging to conduct a similar evaluation of the redesigned DCS displays using the same cohort of subject matter experts. The subject matter experts would have already been exposed to the earlier displays, thus biasing their assessment of redesigned displays. Because of the need to enlist a new group of subject matter experts and the difficulty in finding equally qualified subject matter experts, heuristic evaluation provides only a glance at issues prior to implementing design recommendations. The efficacy of the redesigns remains a face validation rather than a formal validation.

The solution to these shortcomings is to benchmark operator performance on existing and improved DCS displays. This is possible within a control room simulator like the reconfigurable control room simulator facility at Idaho National Laboratory (Boring et al., 2012). It is possible to test the same set of operators with the existing and improved DCS, although some familiarity effects of the operators to particular DCS displays may confound the results. Given the comparable training and experience of most licensed commercial reactor operators, it is also possible to perform a between-subjects evaluation, in which different crews are exposed to different interfaces. Suitable metrics, e.g., time to perform task, operator 
accuracy, and operator preference, can be compared between different versions of the DCS. The objective of the DCS redesign is to improve all measures, thereby ensuring successful and safe operator interactions with the DCS.

Of final note, existing analog control systems are typically capable of displaying process parameters such as flow, temperature, pressure, level, and other directly-measured values, and often involve only feedback control. This report addresses ways to enhance the displays of parameters in the DCS. Note that the capabilities of DCSs could allow a range of additional control and HSI enhancements that, while beyond the scope of this report, would be interesting and potentially very useful future studies. Several parameters could be combined using suitable algorithms to describe the value and trend of functions, with drill-down pages for the individual parameters. For example, the function of adequately depressuring and cooling a pressurizer level-dependent flow rate of reactor coolant just upstream of the chemical and volume control system ion exchangers could be described by one or two synthesized functions rather than several pressures, temperatures, and valve positions. Other functions such as departure from nucleate boiling and heat transfer rate that describe the engineering operation of a piece of equipment or system could also be inferred from several parameters and would provide the operator with fewer individual items to monitor. DCSs could clearly and accurately identify malfunctioning instruments. They could project trends of parameters and functions into the future, thereby providing the operators with advanced warning of degradation or adverse trends. The ability to project trends and integrated feedforward control of several systems could be valuable if plants were to load follow and to facilitate increased resilience to moderate and severe grid transients. In short, while there exists a strong need to provide guidance for the proper design of replacement HSIs in the control room, the design of replacement HSIs should not overlook the opportunity to gain new functionality - new controls and new, smarter indications - than was possible prior to DCSs. Effective interface design for digital control systems should not only avail itself of solid design principles for the digitized like-for-like replacements of analog instrumentation and controls; it should also capitalize on the capabilities inherent to the digital architecture in order to realize smarter, next generation interfaces. Future guidance documents will aim to incorporate style guide elements for both replacement I\&C and advanced HSIs. 


\section{REFERENCES}

Boring, R.L., Agarwal, V., Joe, J.C., \& Persensky, J.J. (2012). Digital Full-Scope Mockup of a Conventional Nuclear Power Plant Control Room, Phase 1: Installation of a Utility Simulator at the Idaho National Laboratory, INL/EXT-12-26367. Idaho Falls: Idaho National Laboratory.

Boring, R.L., Gertman, D.I., Joe, J.C., \& Marble, J.L. (2005). Proof of concept for a human reliability analysis method for heuristic usability evaluation of software. Proceedings of the Human Factors and Ergonomics Society 49th Annual Meeting (pp. 676-680. Santa Monica: Human Factors and Ergonomics Society.

Chambers, J., Cleveland, W., Kleiner, B., \& Tukey, P. (1983). Graphical Methods for Data Analysis. Belmont, CA: Wadsworth.

Duncker, K. (1945). On problem-solving. In John F. Dashiell (ed.), Psychological Monographs (vol. 58, pp. 1-114). Washington, DC: American Psychological Association, Inc.

Ericsson, K., \& Simon, H. (1993). Protocol Analysis: Verbal Reports as Data (2nd ed.). Boston: MIT Press.

Francis, G., \& Reardon, M. (1997). Aircraft Multifunction Display and Control Systems: A New Quantitative Human Factors Design Method for Organizing Functions and Display Contents, USAARL Report, No. 97-18. Fort Rucker, AL: United States Army Aeromedical Research Laboratory.

Hollifield, B., Oliver, D., Nimmo, I., \& Habibi, E. (2008). The High Performance HMI Handbook. Houston: PAS.

Hwang, S.-L., Liang, S.-F.M., Liu, T.-Y. Y., Yang, Y.-J., Chen, P.-Y., Chuang, C.-F. (2009). Evaluation of human factors in interface design in main control rooms. Nuclear Engineering and Design, 239, 3069-3075.

International Society of Automation. (1985). Graphic Symbols for Process Displays, ISA-5.5-1985. Research Triangle Park, NC: International Society of Automation (formerly Instrumentation, Systems, and Automation Society).

International Society of Automation. (2009). Management of alarm systems for the process industries, ANSI/ISA-18.2-2009. Research Triangle Park, NC: International Society of Automation.

Kirmani, S., \& Rajasekaran, S. (2007). Heuristic evaluation quality score (HEQS): A measure of heuristic evaluation skills. Journal of Usability Studies, 2(2), 61-75.

Kemeny, J. G. (1979). Report of the President's Commission on the Accident at the Three Mile Island: The Need for Change: The Legacy of TMI. Washington, DC: President's Commission.

Lau, N., Skraaning Jr., G., Eitrheim, M. H. R., Karlsson, T., Nihlwing, C. \& Jamieson, G. A. (2011) Situation Awareness In Monitoring Nuclear Power Plant: The Process Overview Concept And Measure, HWR-954). Halden, Norway: OECD Halden Reactor Project.

Lavidor, M., \& Ellis, A. W. (2001). Mixed-case effects in lateralized word recognition. Brain And Cognition, 46(1-2), 192-195.

Lee, E. \& Macgregor, J. (1985). Minimizing user search time in menu retrieval systems. Human Factors, $27(2), 157-162$.

Matthews, M. D., Beal, S. A. (2002). Assessing Situation Awareness in Field Training Exercises, Research Report 1795. Fort Belvoir, VA: U.S. Army Research Institute for the Behavioral Sciences.

Mejdal, S., McCauley, M. E., \& Beringer, D. B. (2001). Human Factors Design Guidelines for Multifunction Displays. Washington, DC: Office of Aerospace Medicine.

Naser, J., Fink, R., Hill, D., \& O'Hara, J. (2004). Human Factors Guidance for Control Room and Digital Human-System Interface Design and Modification: Guidelines for Planning, Specification, Design, Licensing, Implementation, Training, Operation and Maintenance, EPRI TR-1008122. Palo Alto, CA: Electrical Power Research Institute. 
Naser, J., O’Hara, J., Pirus, D., \& Beltracchi, L. (2003). Information Display: Considerations for Designing Modern Computer Based Display Systems, EPRI TR-1002830. Palo Alto, CA: Electrical Power Research Institute.

Nielsen, J. (1994). Enhancing the explanatory power of usability heuristics. Computer-Human Interaction (CHI) Conference Proceedings (pp. 152-158). New York City: Association for Computing Machinery.

Paap, K., \& Cook, N. (1997). Design of menus. In M. Helander, T. Landauer, \& P. Prabhu, P. (eds.), Handbook of Human-Computer Interaction (pp. 533-572). Amsterdam: Elsevier Science Pub.

Patrick, J., James, N., Ahmed, A., \& Halliday, P. (2006). Observational assessment of situation awareness, team differences and training implications. Ergonomics, 49(4), 393-417.

Sheedy, J.E., Subbaram, M., Zimmerman A.B., \& Hayes, J.R. (2005). Text legibility and the letter superiority effect. Human Factors, 47(4), 797-815.

U.S. Nuclear Regulatory Commission. U.S. NRC Nuclear Concepts Course Manual. Retrieved from website: www.nrc.gov/reading-rm/basic-ref/teachers/03.pdf

U.S. Nuclear Regulatory Commission. (2011). Westinghouse Technology Systems Manual. Retrieved from website: pbadupws.nrc.gov/docs/ML1122/ML11223A214.pdf 


\section{APPENDIX A: Description of DCS Display Prototype Tool}

In order to make the design recommendations given in this report more useful, a series of static images were generated to accompany them. The application, TiJo Lite, was designed to aid in the development of new digital control system (DCS) displays for nuclear power plant control rooms, with particular emphasis on the chemical and volume control system (CVCS) covered in this report. TiJo Lite is a graphical manipulation tool that allows a user to easily import and manipulate items commonly found on a control room display, including pumps, pipes, and valves. Users lay out these items using the pointand-click function of the mouse. TiJo Lite was created primarily as a prototype tool to redesign the CVCS displays for this report, but has the capability to design new DCS displays beyond the CVCS. TiJo Lite is currently only available for in-house work at Idaho National Laboratory.

TiJo Lite is a Windows Forms application, designed using Microsoft Visual Studio 2010 and coded in C\#. The primary objective of this program was to be able to import, edit, and export images related to DCSs. That goal was broken down into customizing different parts of the images such as the background, the objects themselves, the small windows, the buttons and text items. An added feature was the ability to save and open previous layouts and continue to edit them. Another key objective of the program was the ability not only to add and manipulate small windows but also edit them, add custom windows, and save and open the edits as well.

Figure A - 1. Prototype Tool Menu Structure

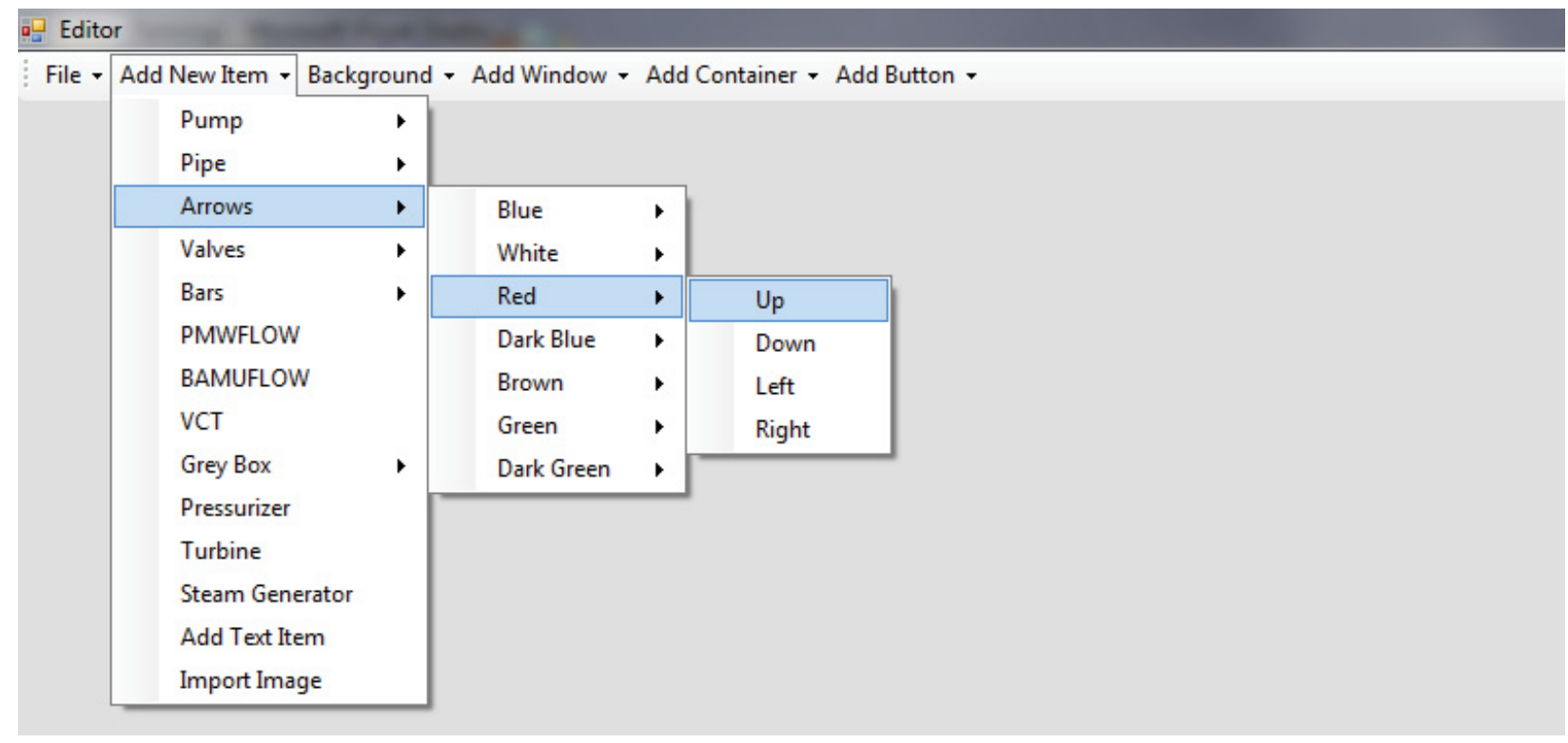

There are several features that make TiJo Lite more useful than commercially available programs for redesigning DCSs. For instance, the tool is vendor independent, allowing HSI design across DCS platforms. In addition, all of the DCS items are actually editable Windows objects, which means they can be manipulated with the click of the mouse. Items can be imported using the drop-down menus in the upper left of the screen. Menus are organized by item type; many are multi-tiered (see Figure A - 1). Users use the mouse to navigate through the tiers of item menus. For instance, if the user wanted to choose a red arrow that pointed upwards, they would hover over the "Arrows" tab, move the mouse over the "Red" tab, and then click on "Up". 
The program contains several pre-loaded backgrounds, which can be imported under the Background tab. On top of these, the user can import commonly used items such as a pump, a valve, pipe or tank. TiJo Lite contains many importable valves and tanks specific to the CVCS system (see Figure A - 2). If a user needs unusual items for a system redesign, TiJo allows them to import custom items. Custom items can be added through the "Add New Item" drop-down menu.

\section{Figure A - 2. Predefined CVCS Objects}

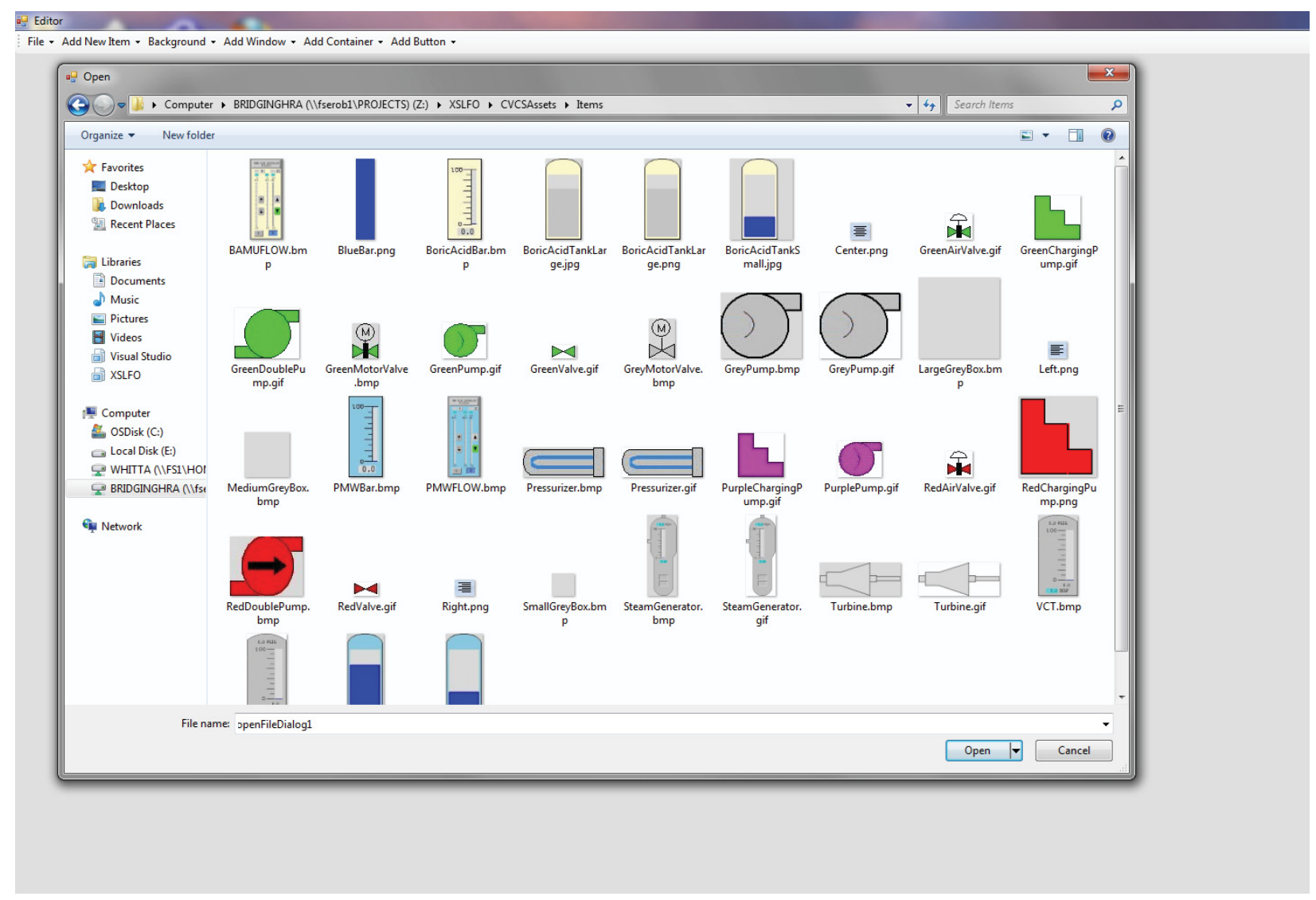

Figure A - 3. Object Menu

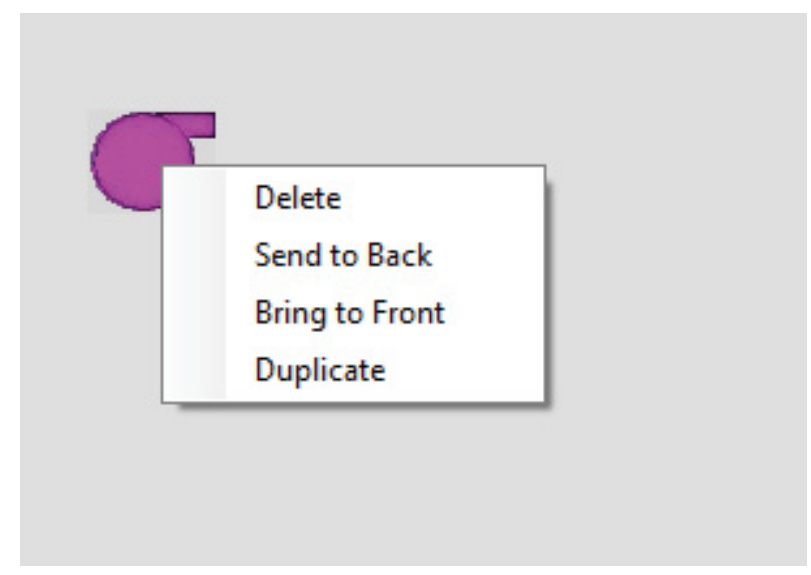


Users only have to import images once. The right-click menu (see Figure A - 3) contains a Duplicate function, which allows the user to copy custom items and avoid repeating the import process. Also on the right-click menu are the options to delete the item, send the item to the back or bottom-most visible layer, and bring the item to the front or top-most visible layer.

Users can also add custom backgrounds (see Figure A - 4) to the editing area, e.g., a screenshot of the DCS that is being redesigned. This is in addition to the preset background images, which are screenshots of the CVCS DCS displays under review for this project.

Figure A - 4. Insert Background Menu

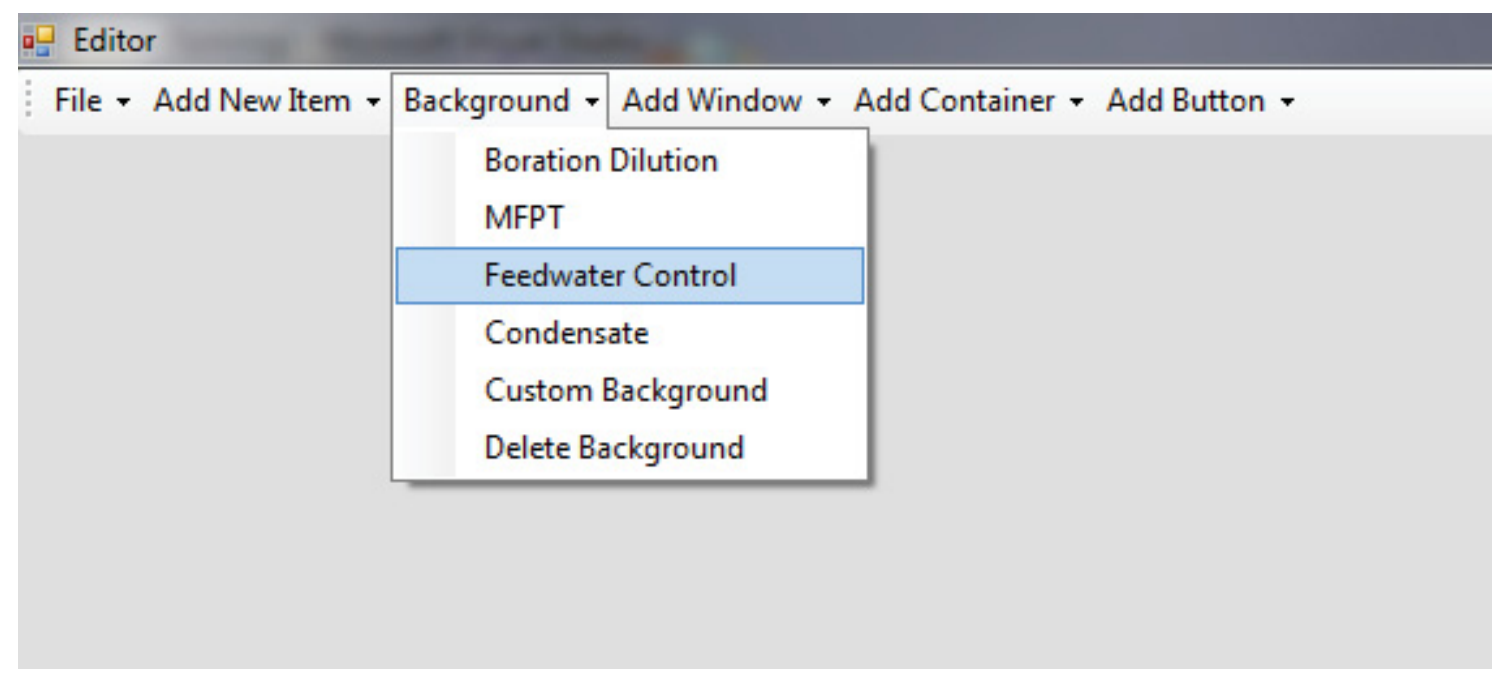

Figure A - 5. Add Container Menu

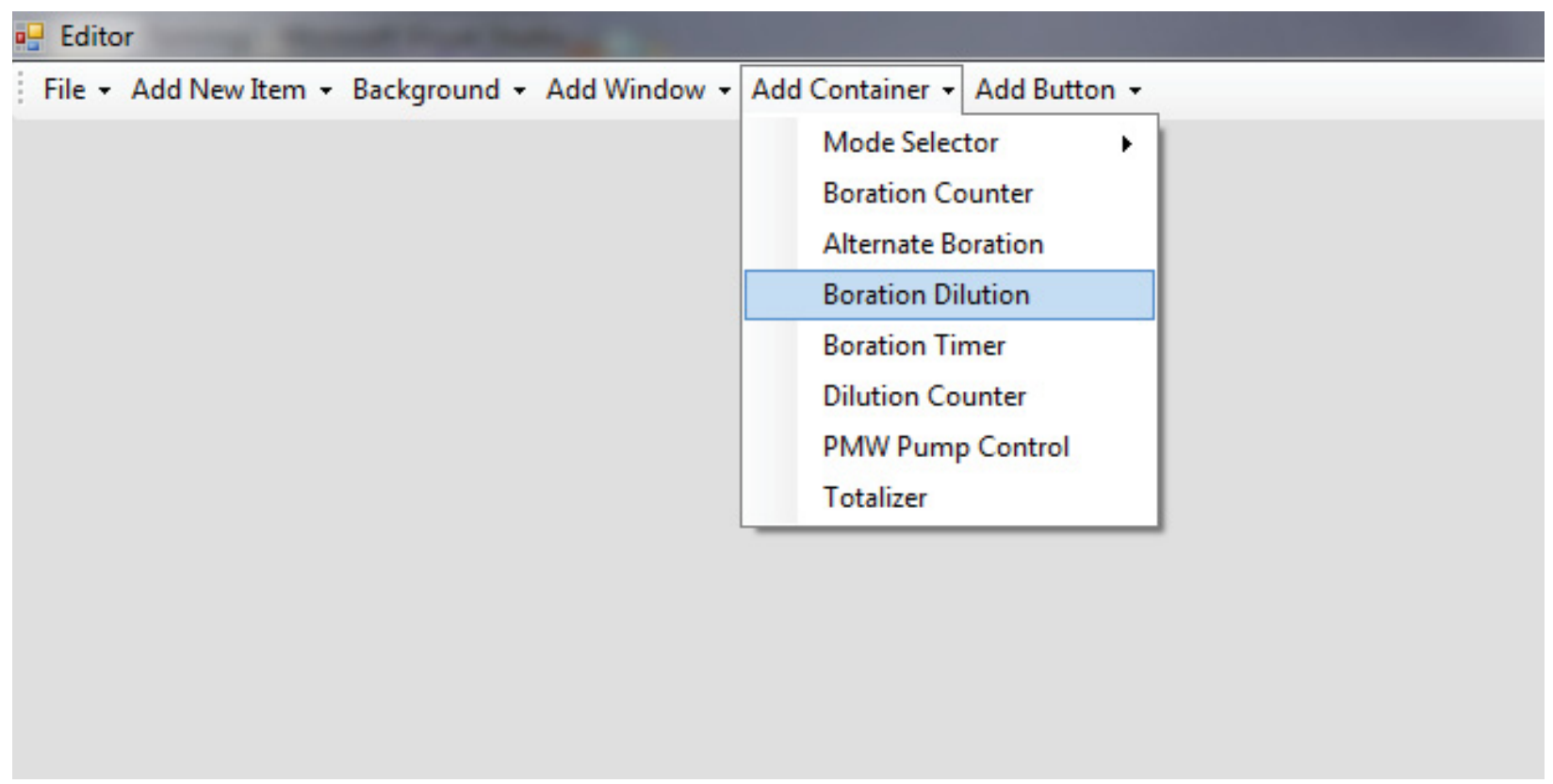


The "Add Container" drop-down menu in the toolbar (see Figure A - 5) is similar to the "Add New Item" option, except it is filled with specific types of items. These are containing elements within the current DCS such as menus, controllers, and various other items that contain important data. A separate toolbar drop-down menu was created for this to designate its importance and to prevent crowding of the "Add New Item" menu. Items from this menu can be edited and manipulated just like any other item.

\section{Figure A - 6. Add Button Menu}

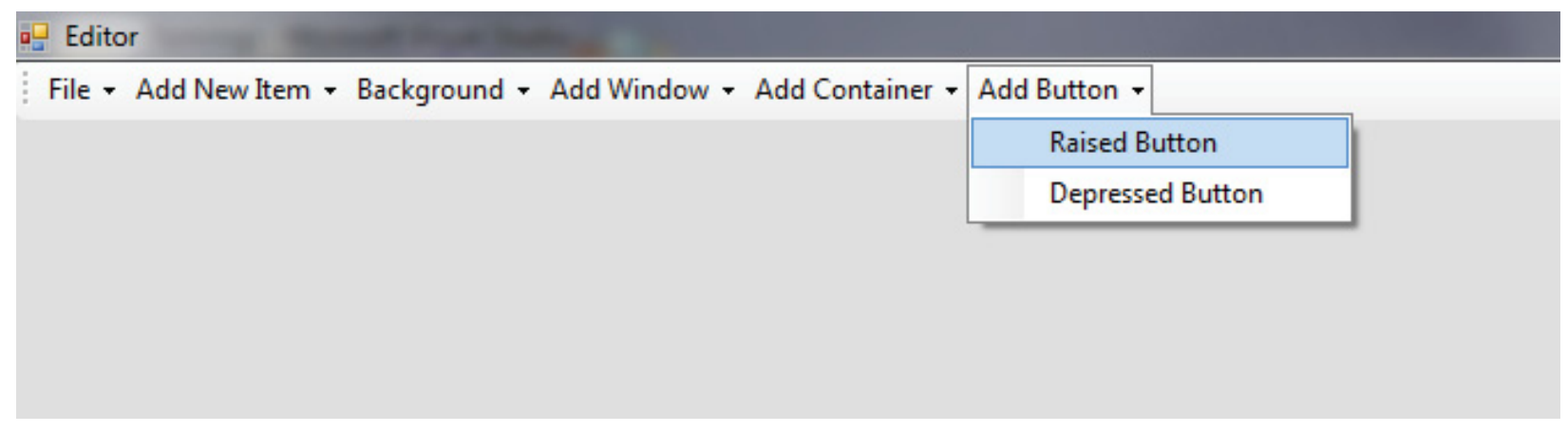

The toolbar also gives the user the option to create custom buttons, either raised or depressed (see Figure A - 6). If either of these options is clicked, a dialog box comes up that allows the user to edit the text that appears within the button, along with the font, font color, background color, and text alignment. The reason this function was added was because much of the terminology and typography that needs to be edited in the DCS is in fact embedded within a button.

Figure A - 7. Custom Window Tool

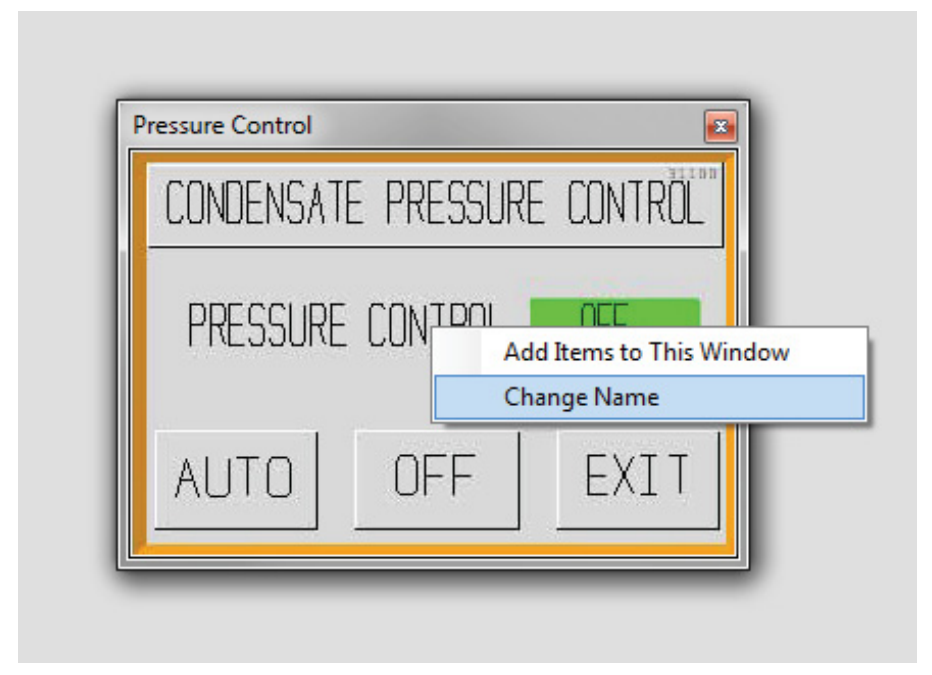

One requirement of this prototyping tool is to have the ability to add small custom windows (e.g., pop-up windows), and to be able to manipulate them around the screen. The user can select one of several small windows from a drop-down menu or choose to add a custom window (see Figure A - 7), and this window will appear on top of the current screen: an image with a window border and close function in the upperright-hand corner. If the user right-clicks within this window they have the option to either rename the window or to add items to it as they would within the regular editing area. This makes it possible to edit the text, buttons, or colors within the window. TiJo Lite treats windows like small editing areas when 
selected, and like objects when not. When the user saves the layout, the small windows and any customizations to them are also saved.

Figure A - 8. Grey Box Feature for Editing Existing Displays
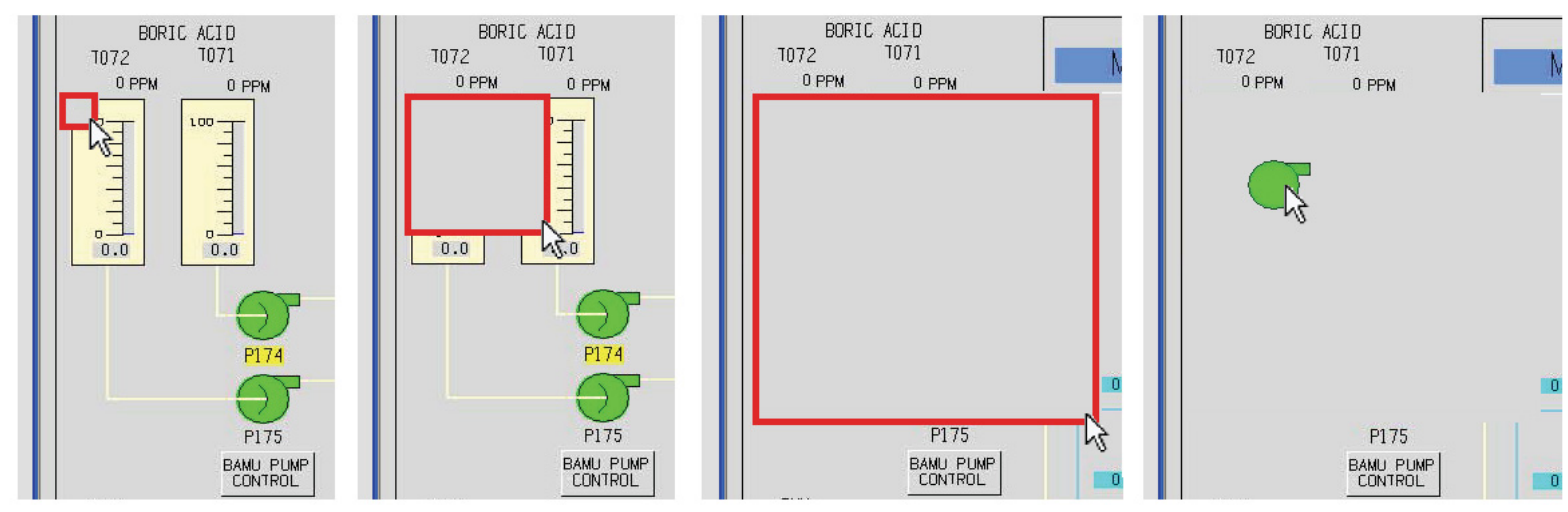

A key method of editing DCSs with TiJo Lite is to use the grey box item supplied in the "Add New Item" drop-down menu. Imported backgrounds contain objects that cannot be manipulated or deleted individually. Grey boxes can be used to cover up certain portions of the screen to clear space for new items (see Figure A - 8). The grey box, and any other graphical and text item for that matter, can be resized by left-clicking on the desired item while holding down the middle-mouse button and then dragging the grey box until it reaches the desired size. Because the grey box has the same fill color as the background color of the DCS, it makes the DCS appear as if there is simply a blank spot on the screen. New items can then be placed on top of the grey box as desired.

Figure A - 9. Text Insertion Feature

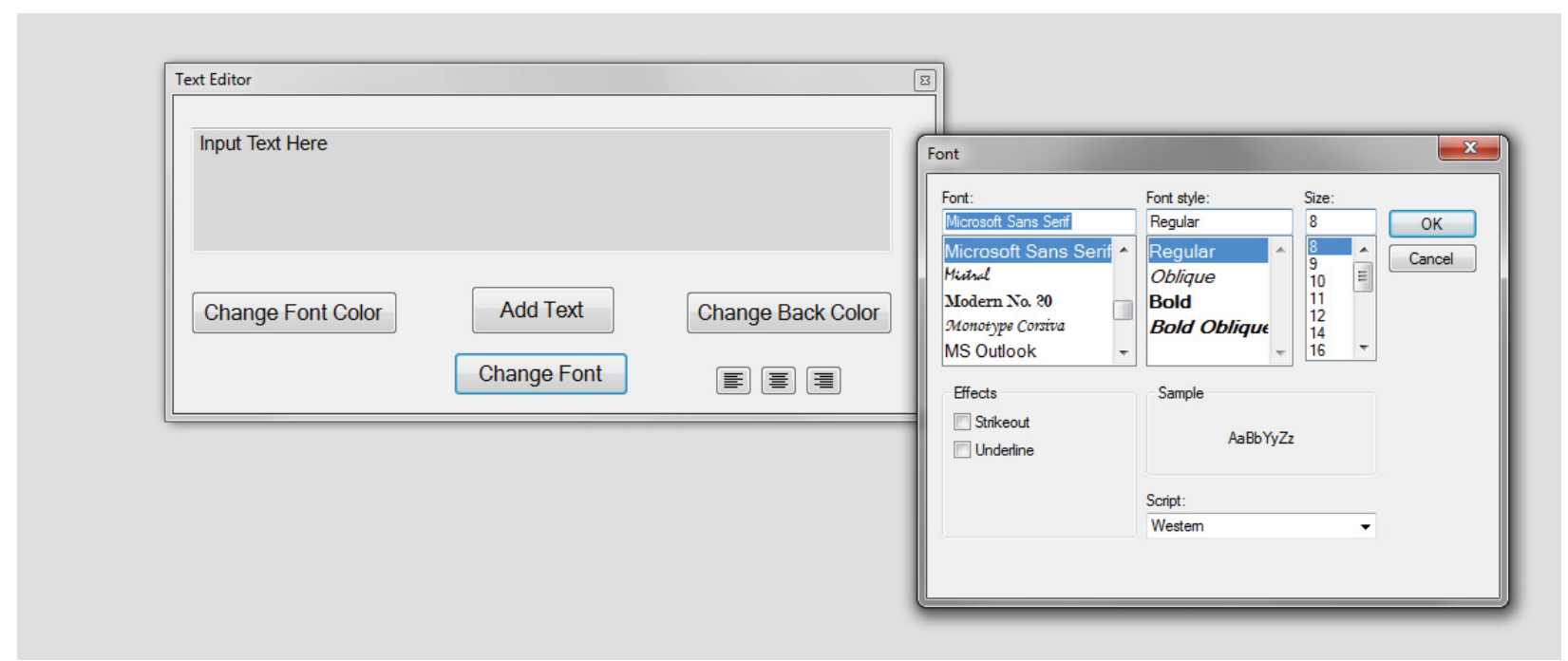

The user has a wide range of options when adding custom text. The custom text option can be found inside the "Add New Item" drop-down list. Selecting this option will bring up a dialog window named "Text Editor," inside of which the user can find a text entry box and several buttons (see Figure A - 9). These buttons allow the user to change the font color, the background color, the font itself (which includes font size, weight, family, etc.), and the text alignment. To confirm these changes, the user clicks the "Add Text" button, and the text item will be added to the editing area with the ability to be 
manipulated just like all the other graphical items. The background of the text can be stretched like a grey box without changing text size.

Figure A - 10. File Menu

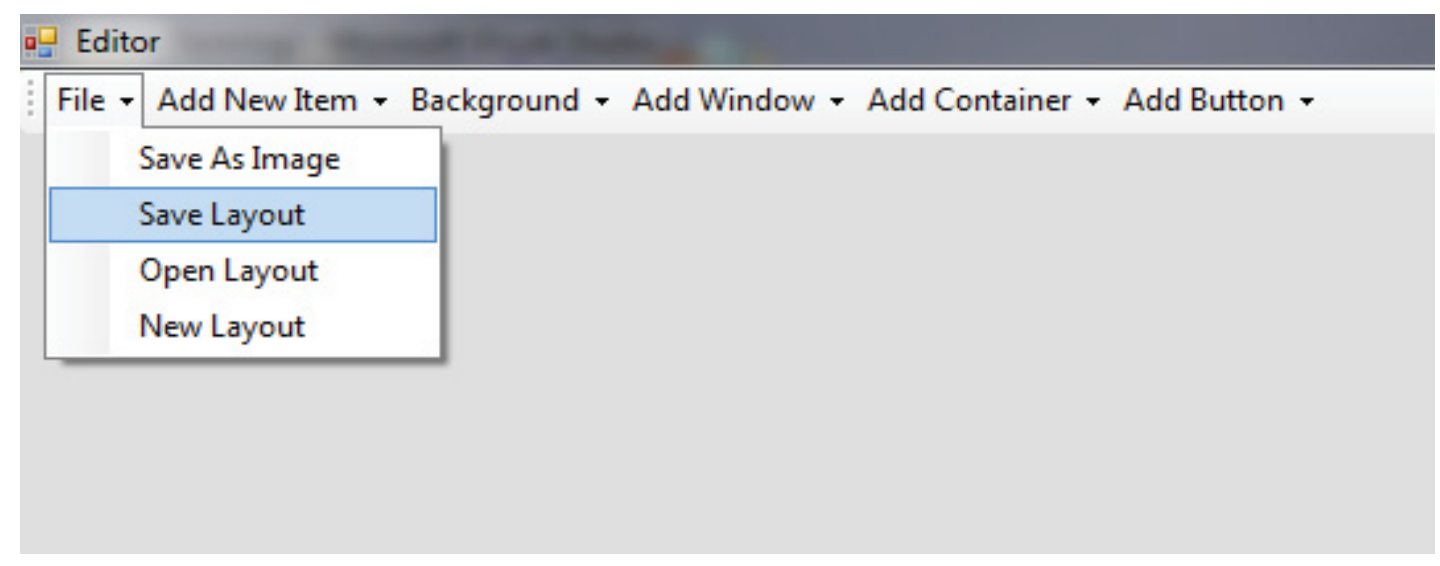

TiJo Lite saves both project and image files. Layouts can be saved to open later in the software, and images can be exported to use elsewhere (see Figure A - 10). The updated DCS displays in this report were exported from TiJo Lite. The "File" drop-down menu in the toolbar has four options: Save as image, Save layout, Open Layout, and New Layout. The "Save as Image" option exports a picture of the entire editor display and brings up a dialog box that gives the user the option to export it to .png, .jpg, .gif, or .bmp file formats. The "Save Layout" option enables the user to save the positions of all the items added, as well as the background image and any other customizations as a .cves file. This layout can then be opened with the "Open Layout" option, which will enable the user to manipulate all of the previously saved items. The final function in the drop down is the "New Layout" function, which simply clears the editing area of all items and clears the background to start a new DCS display project.

TiJo Lite has been a very useful tool for prototyping redesigns of DCSs for this project. Its graphical editing and manipulation capability has made it ideal for rearranging items within the DCS screens, adding new images to the screens, and changing the terminology and typography of onscreen data. It was found to be particularly useful for quickly evaluating different design proposals and turning them into useful recommendations. Items on the screen could be quickly moved around, removed if necessary, saved and reopened, resized, and edited in any other way that was necessary to turn an idea into a design recommendation.

In the future, it is anticipated that TiJo Lite will be a helpful tool for human factors researchers attempting to optimize other DCSs. As more systems in NPPs go from analog to digital, TiJo Lite will likely see use as both a tool to create new DCS displays and to edit current screens. TiJo Lite could also be ported to a Java program/applet. As a Java program, TiJo Lite could run on both the Windows operating system and other operating systems. For those designing the actual software that runs the DCSs, TiJo Lite is also a useful tool for rapid display prototyping. The software can provide a solid link between human factors researchers, designers, and software developers to ensure DCS display optimization. 